DOE/SR/18217-4

\title{
CANCER AND BIRTH DEFECTS SURVEILLANCE SYSTEM FOR COMMUNITIES AROUND THE SAVANNAH RIVER SITE PHASE I - CANCER
}

TECHNICAL PROGRESS REPORT - YEAR 04

JOHN B. DUNBAR, D.M.D., Dr.P.H.
DEPARTMENT OF BIOMETRY AND EPIDEMIOLOGY MEDICAL UNIVERSITY OF SOUTH CAROLINA CHARLESTON, SOUTH CAROLINA 29425

DATE PUBLISHED - MAY 1995

PREPARED FOR THE

US DEPARTMENT OF ENERGY

UNDER GRANT DE-FG09-91SR18217

\section{DISCLAIMER}

This report was prepared as an account of work sponsored by an agency of the United States employees, makes any warranty, States Government nor any agency thereof, nor any of their bility for the accuracy, completeness, or implied, or assumes any legal liability or responsiprocess disclosed, or represents that, or usefulness of any information, apparatus, product, or ence herein to any specific commercial use would not infringe privately owned rights. Refermanufacturer, or otherwise does not necessarily const, or service by trade name, trademark, mendation, or favoring by the not necessarily constitute or imply its endorsement, recomand opinions of authors expressed herein Government or any agency thereof. The views United States Government or any agency there not necessarily state or reflect those of the 


\section{DISCLAIMER}

Portions of this document may be illegible in electronic image products. Images are produced from the best available original document. 


\section{SRRHIS TECHNICAL PROGRESS REPORT YEAR 04 \\ TABLE OF CONTENTS}

Page

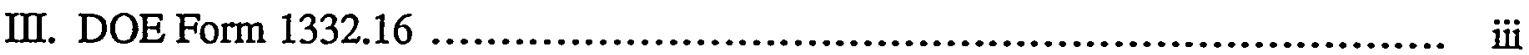

IV. Technical Progress Report Grant Year 04 ........................................ 1

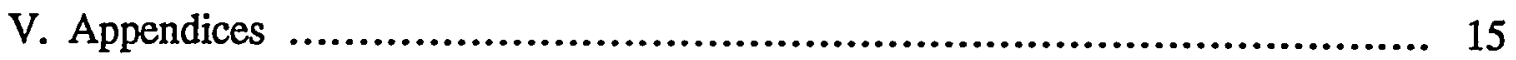

Appendix A - Presentation to the Steering Committee: "Redefining Boundaries of a Geographic Cancer Registry Through Cooperation and Collaboration: SRRHIS"

Appendix B - List of Community and Hospital Outreach Activities...................... 18

Appendix D - Professional Outreach Activities

Poster Session - The Relationship between Perceived Health Risks and Cancer Mortality Data for Areas Proximal to the Savannah River Site

Poster Session - The Development and Implementation of a Geographic Analysis System for Population Health and Environmental Risk Assessment

Oral Presentation - Geo-Coding of Health and Demographic Data as a Resource for Environmental Incidents Preparedness and Response

Oral Presentation - Multiple Data Sources and Effective Quality Control in Geographic Cancer Registry Operations

Appendix E - Staff Educational Outreach Activities................................ 56

lemour Appendix F - SRRHIS Newsletters in Grant Year 04 .............................. 58

Appendix G - Savannah River Region Health Information System - Brochure ..... 67

Appendix H - CTR Examination Review Workshop and Advanced Cancer Registry Training Program Brochures

Appendix I - Steering Committee Members and Steering Committee By-Laws .... 71

Appendix J - Emory University Technical Progress Report Grant Year 04 ........... 77

Appendix K - Steering Committee Meeting Agendas .............................. 86 
DE-FG09-91SR18217-4

\title{
CANCER AND BIRTH DEFECTS SURVEILLANCE SYSTEM FOR COMMUNITIES AROUND THE SAVANNAH RIVER SITE
}

\author{
Savannah River Region Health Information System (SRRHIS) \\ TECHNICAL PROGRESS REPORT FOR YEAR 04 \\ CANCER GRANT - PHASE 1
}

\section{GOALS FOR THE SECOND GRANT PERIOD AND YEAR 04 PROGRESS}

Year 04 began the second three-year grant period, the overall goals of which were to consolidate and continue the aims of the first period, with the important exception that a great deal more effort would be expended on promoting community awareness and knowledge, as these characteristics relate to the residents' perceptions of major potential health effects. It was anticipated that more time would be available during the second period to accomplish this aim because the difficult early work of gaining hospital and community acceptance would have been done. Specifically, the goals were to:

1) Maintain and refine the cancer registry;

2) Inaugurate the birth defects registry if it were funded; and

3) Enhance community involvement and education.

Maintaining and refining the cancer registry: The cancer registry is an established regional program. That is to say, the SRS area hospitals are cooperating fully, the staff of cancer registrars has been replenished, and the cancer data for the years 1991-93 has been largely collected. All the hospitals of the immediate SRRHIS region were visited individually in year 04 , and 1991 data summaries presented to their cancer program committees. Also, data summaries were mailed to all hospital administrators with the offer for us to make a market-type presentation should they have interest. Five of them did.

After the three-years pool of data is in place and quality-controlled, the information will be disseminated widely within the SRRHIS region. The 1991 data were widely noted on the speaking and interview tours around SRRHIS communities, but the listeners were promised the 1991-93 information would permit a more detailed estimation of cancer occurrence rates. With that aim in mind, we put substantial effort into quality control during year 04.

Quality control is a large and complex issue. On the one hand there are individual records and data elements to check and recheck. Ms. Seltz already is handling this demanding job of quality control of individual records. To assist the process and at the same time to assure standard records assessment and interpretation across the state line, the Emory SEER QC editor developed a set of 20 fake-name cancer records for independent review by abstractors in SC and those in GA. The QC editor found few "mistakes", and most of these were of a minor sort. The differences were discussed with the abstractors as a reminder to stay with the Operations Manual even with seemingly minor fields of information. It was an effective learning tool, and the Steering Committee (which asked us to cross-check abstracting methods for both states), was pleased with the report. We also had a consulting visit from Dr. Dee West, Director of the Northern California Cancer Registry (a gold standard operation) to assess our operations, and to speak to our Steering Committee.

Missed cases are another matter; quality will not be assured if we miss cases. Even worse, community credibility would be lost if it became known we missed a case of cancer, particularly 
a case of one of the closely watched cancers like leukemia. So we took steps to avoid the problem. In the quest for maximum completeness of data reporting, it is necessary, for example, to enlist the help of all pathologists who analyze specimens from our project counties. Some of the pathologists are located outside the region, such as a private laboratories in Columbia and Charleston. We kept them informed through their officers and through announcements at their annual meetings, and expect to retain their cooperation. To this end, in year 04, a great deal of time was taken to visit them and assure them that their records will be carefully guarded for confidentiality. This is a continuing major effort. We also have to affirm completeness of case finding by comparing our case files with state death files. With the help of DHEC vital records director, Mr. Murray Hudson, the 1991 data was matched against the death records in this project year. Finally, Dr. Lackland worked closely with the State of SC Budget and Control Board to compare our data files to those of the UB 92 system (hospital discharge records). Although a great deal of work will be required to make the two data sets compatible, the exercise has already helped in defining referrals and should detect any missing cases.

We have close relations with the area cancer registrars, having helped them in sponsoring training and professional meetings. We have found that these activities gave the SRRHIS program important publicity and prompted our acceptance as the registry leader for the region. Further to this reputation, and as a service to the hospitals which allow us to abstract their records, we provide consultation to individual hospital registries without charge. To this end, in year 04 SRRHIS, in cooperation with the SC Tumor Registrars Association, planned and conducted the second annual training program. It attracted more than 80 participants from 10 different states and Puerto Rico.

As noted earlier in the quality control discussion, we worked as one with Emory University to assure our methods and data are uniform. Further, the staff developed a format for merging the case data from the two states. This exchange of data was made possible by the agreement of the two state health departments, after a request from SRRHIS. Let me reiterate, this close working relationship across a state line is essential to the quality and completeness of reporting, and to the aim of making residents of the two sides of the River sense their unity of interest.

In year 04 the relationship of SRRHIS to the South Carolina Central Cancer Registry (DHEC, begun in the summer of 1993) deepened, and the potential mutual benefits could be appreciated even more. SRRHIS is a partner in this state-wide effort which was born from the confidence engendered by the success of the SRRHIS registry. We arranged a pilot data-swap with DHEC, so that non-SRRHIS county data collected in SRRHIS counties was given to them, and SRRHIS county data from other parts of the state was given to us. DHEC was responsible as well for helping with the death matching, noted above in the discussion about missed cases. Further discussions were had with DHEC about a Quality Control Editor to be hired and assigned to SRRHIS for facilitating data collection from hospitals, clinics, and pathologists around the state, outside the SRRHIS area. This position, expected to commence in year 05, will be of great assistance to the SRRHIS cancer registry process and data quality.

The issue of whether to include additional health-related endpoints was explored with the assistance and advice of scientist colleagues at several federal agencies and universities. During a recent scientific meeting at Rutgers, discussions about techniques for measuring exposures of SRS residents to various hazardous chemicals, and to low dose radiation, brought into sharp focus the paucity of health outcomes data. The current dose reconstruction around the SRS, being undertaken by RAC and funded by CDC, will provide estimates of exposures to populations and to individual persons. The SRRHIS program will be able to provide a few years of cancer incidence data. Mortality data, of course, is available for all years and for all disease endpoints. However, more subtle endpoints, such as neural, immuno-suppressant, and/or renal changes measurable in body fluids, or health changes discernible through medical history, will 
not be available unless steps are taken soon to establish baseline data. These possibilities are under discussion, but no actions were taken in the year.

Additional details about the activities comprising the year 04 progress report are presented in the later section of this report entitled, WORK PLAN AND EVALUATION,
YEAR 04.

Inaugurating the birth defects registry: The birth defects registry was funded during year 04 of the parent grant (cancer grant), but it has been treated as a separate project with a different start date. It began its first year on September 30, 1995 and has enjoyed a successful period of planning and early data collection. That progress report will be forthcoming at the end of October 1995, and the continuation application will be submitted before the end of June 1995.

Enhancing community involvement and education: Effective and continuing communication with the SRS public was an overriding concern of the Principal Investigator and the staff in year 04. Steering Committee meetings were announced in the newspapers and by mail ahead of time, and they were held in the evenings to promote attendance by interested lay persons and to accommodate working family members. Still few community residents showed up. At the meeting in Savannah in April 1995 we expected at least some citizens to show up because we announced that a guest speaker would be talking about the transport of spent fuel rods to the SRS area. Not onie resident appeared. This observation affirmed an earlier decision to focus attention on getting to groups of residents at places and occasions where they already meet in the regular course of their lives. This idea was expressed succinctly in a letter (in 1991) to Dr. Dunbar from Mr. Brian Costner, Executive Director of the SC Energy Research Foundation. It is reproduced here as a good general expression of how we are organizing our community
activities:

"With this letter, I'm putting in writing some of the ideas we've discussed regarding public communication and the SRRHIS registry. I've attempted to suggest a direction you might pursue rather than a detailed plan for changing your approach. Please don't hesitate to call me with any questions. Feel free to distribute this letter to the SRRHIS Steering Committee and other interested persons.

The registry is a process for data collection which won't even be in a position to report meaningful numbers for a few years. When there are results to report - and particularly if those results suggest a need for additional research - the public communication and involvement tasks will be greater. For now, perhaps the goal of a public communication program should simply be to let people know that a registry is being established and to explain some of its benefits and limitations.

There are several opportunities for talking about the registry to citizens in the Savannah River region. Up to now, the SRRHIS approach has been to host meetings focused solely on the registry. This is important when and if people in an area express a concern about the registry, but may not be the most effective way to introduce the registry to people unfamiliar with it. The recent public meeting in Augusta and feedback from the meeting in Hampton demonsirate this.

Presentations on SRRHIS should be offered when they're wanted and should be available to a wide range of groups throughout the region. There 
are several ways to accomplish this. For example, you might work with hospitals and cancer treatment centers to arrange small, informal meetings with a more targeted audience. Such a meeting might be similar to the one held in Hampton. Also, you might contact organizations that have regular meetings such as the Sierra and Rotary clubs and other environmental and civic groups.

Perhaps you could get 20-30 minutes on the agenda at several of these meetings. Finally, having brochures and, when possible, staff at meetings hosted by others on Savannah River Site (SRS) issues could continue and even be expanded. These last two approaches have the benefit that SRRHIS staff don't have to create the forum and attract the audience."

To this end, in year 04 a great deal of effort was spent making presentations to interested groups of residents. Further, a special effort was made to assure that minorities, rurals, and females were represented in the audiences. As can be seen from a review of the appended list, Hospital and Community Qutreach Year 04, considerable progress was made in informing the regional public about the existence and purposes of the program. Dr. Dunbar spoke to over 130 residents in direct appearances before them, and spoke to many more via two TV interviews and one radio talk show. Comments from the TV hosts indicate there was good public reaction. The radio appearance was a different and surprising story. Two persons showed up before the interview began and one showed up afterwards to ask questions about their concerns. But that was not the surprise. The surprise came two weeks later when Dr. Dunbar was in Blackville for a reception (attended by 97 residents), and was told by four different residents (two black, two white) that they heard his comments, and the two Steering Committee members present said the presentation was the best they had ever heard. The radio host had announced Dr. Dunbar's appearance long before he actually came. Other radio shows are planned. There are 59 radio stations up and down the Savannah River counties, and so far each one called has indicated interest. Only a few of them will be called the next year, just enough to make good geographic coverage a high probability. Then, after the 3-year's worth of data is in by early 1996, the round of talks and civic group presentations will begin again.

We were pleased to find that civic groups do include females and minorities in their membership roles, but the proportions continue to be low. We have been in contact with the League of Women Voters in Beaufort/Hilton Head, and expect to make inroads in that direction. No good way other than radio has been used to address the rural residents. Next year we plan to poll the residents, including rurals, to ascertain their awareness of the project.

Our Newsletter continued to be of great value in communicating with the SRS residents. Three were prepared and mailed out in year 04. It was well received judging from comments and the mailing back of postcards from a large mailing list. It will continue to present ideas and issues related to the registries, and be prepared and mailed, usually four times annually, each time corresponding with the Steering Committee quarterly meetings. It featured articles from representatives of our hospitals, cooperating professionals, and collaborating organizations such as DHEC. This policy will be continued because it enhances the networking of interested parties, an essential ingredient for the long term health of the program. Further, articles on the understanding and prevention of certain cancers, as well as discussions of our 3-years of data, will begin to appear in future editions. 
On the professional side, several presentations were made. Dr. Dunbar delivered a paper on "Multiple Data Sources and Effective Quality Control in Geographic Registry Operations" at the NAACCR meeting in April 1995 in San Francisco. Dr. Lackland presented a paper to the American Nuclear Society in Atlanta in April 1995 about the SRRHIS registry data and a geographic information system (GIS) program for identifying adverse health or potential exposure trends. Student research day also featured several papers related to SRRHIS. One of these presentations received a best-paper award.

\section{Administrative Activities in Year 04}

The administration kept the organization focused on the major objectives through actions related to personnel, computer programming, and operations.

\section{Personnel}

The only change of consequence in year 04 was the replacement of one cancer abstractor who wished to return to her home in Ohio. Her replacement is Mary McAbee a Certified Tumor Registrar from Orlando, Florida. She began in January 1995. The Principal Investigator expects to continue his 35 percent level of effort on this component of the program (cancer registry and community outreach). Other faculty and technical staffing levels appear to be adequate.

\section{Computer Equipment and Programming}

The basic database structure has been implemented using the INGRES DBMS on the DECStation for over a year. Currently we are developing a series of user-friendly programs with graphical user interfaces. Programs for importing data from the Cansur/Net database, and for editing or viewing individual records, have been operational for several months. Another, which allows selected cases to be exported in the format specified by the North American Association of Central Cancer Registries, has recently been completed. A flexible program for generating data for cancer incidence reporting also is under development. It will allow the user to define several parameters such as age group, race, and type of cancer. It also will permit saving the data in separate files which can then be imported into spreadsheet programs. A final program will be written to provide an interface for performing database maintenance functions such as backup, recovery, and restructuring of tables.

The programs will be linked by making them accessible through a graphical menu system, also designed by Windows4gl. A comprehensive users manual is being written which describes the best use of the system. To assist in developing the manual by getting feed-back from the faculty and staff, the programmer is giving them a weekly lecture as
each new chapter is written.

\section{Operations}

By utilizing both electronic data submission from SRRHIS hospitals with Cancer Registries and case abstraction by a field staff representative, SRRHIS has attained a $90 \%$ level of completion for participating facilities' 1991 and 1992 data. 1993 data collection is presently underway. To maintain accurate abstracting, with correct application of coding rules and correct data entry, visual edits and computerized edit checks are being performed. To identify problem areas in the data collection phase at hospitals with and without cancer registries, "field" reabstracting audits and "field" completeness in casefinding studies on reportability are conducted. The SRRHIS registry also has the capability to register each case only once by a sophisticated computerized duplication 
removal system that assists the quality control editor to recognize cases similar in predetermined data items. If duplication has occurred, individual reports are combined to reflect only one incidence of cancer. Additionally, data from cases reported by more than one facility are combined by the loading program designed in INGRES Windows for GL. It reflects the most accurate, complete data, utilizing a hierarchical coding system.

To further assure complete case ascertainment, the SRRHIS data base is also being directly compared to registered deaths in Georgia and South Carolina. A followback mechanism will be instituted to investigate all deaths with a contributing factor of cancer recorded on the death certificate, that do not appear in the SRRHIS database. Additionally, a South Carolina/Georgia comparative edit study by an independent examiner to further analyze the assessment of accuracy by the quality control editors took place. The comparative editing study is an acceptable technique for standardization of measuring practice when more than one examiner/editor is employed. The study proved to be a very useful exercise and has become a standard part of the SRRHIS quality control measures. In addition, more difficult sites and codes are also monitored periodically by the quality control editor to evaluate individual consistency in editing practice.

As time permits, development of additional methods and measures of insuring reliability of data, will take place. To assess completeness of data capture, a study to monitor data items reported as "unknown" could be designed. A computerized error count/data change study could be instituted to get a tangible account of the volume of editing necessary to achieve a high level of data quality. Additionally, "formal" development of more process controls (e.g. visual review rejection error rates, eclit check failure rates, \% of death certificate only cases) would benefit measures of cancer registry quality. Increased involvement of the SRRHIS Physician Advisors continues to be a goal for the upcoming year. Evaluation of the registry's data by physicians who specialize in cancer care would be most useful in verifying that the most accurate, complete and logical scenario of a patient's cancer experience is reflected.

The primary hindrance to timely data submission to the SRRHIS cancer registry still remains the lack of a cancer reporting law for the state of South Carolina. Without such a law in place, adherence to acceptable standards is difficult to enforce. Effective process control cannot be achieved without a law and enforcement of consequences, if cases are not reported in a timely manner.

\section{Steering Committee}

The Steering Committee continues to meet quarterly in cities within the SRRHIS area, since its first meeting in Aiken, SC on February 12, 1992. Thirteen meetings have been held as of the end of June 1995. The early meetings were given to organizing the Committee, educating it about what a registry is, and building trust. The Chairman was elected at the second meeting and two subcommittees were named at the following one. Next we began discussing community meetings. A risk communicator from Rutgers, Caron Chess, came to the October 1992 meeting to help both the Committee and the staff understand the benefits and the pitfalls of public communication efforts. Recent meetings have been more concerned with the data emerging from the registry and how to communicate it to the region's residents. They also were reminded of the voluntary role of the hospitals in making the data available to SRRHIS. In recognition of this fact, they voted to send resolutions thanking them for their cooperation.

Mr. Andrew Rea, who has graciously chaired the Committee for almost three years, was replaced by Ms. Mildred Ford at the January 1995 meeting. Ms. Ford was the first 
member of the Committee and her election by the members is recognition of her dedication and contributions. She chaired the April 1995 meeting which was devoted to a discussion of the WSRS meeting (worker mortality study by Dr. Donna Cragle, attended by Dr. Stockwell and me), a summary of the State Health Agreement meeting in Charleston, and a discussion of the "minimum" cancer registry budget requested by the Steering Committee. Next year some time will be taken with Committee members making them familiar with the new birth defects component, and a great deal of time will be allocated to the issues regarding alternative funding. They are very supportive of the project and would like to assist in its continuation.

\section{WORK PLAN AND EVALUATION YEAR 04}

The goals set forth in the first strategic plan continue to set the direction and intent of the project. However, because the original objectives were based in part on the needs of planning and start-up operations, they have been modified to reflect the needs of sustaining the registry and expanding other components of the program. In effect, therefore, the year 04 work plan continues the original vision, and refines it to emphasize present realities. The goals and objectives are presented in outline form to stress major themes. Note that these goals do not correspond exactly to the general goals of the accompanying narrative. This is so because the WORK PLAN goals are articulated to promote objective evaluation of individual accomplishments.

GOAL 1. Maintain and improve the state-of-the-art health information system.

Objective 1: Implement a system of cancer surveillance with case ascertainment such that comparison with other internationally recognized systems is fostered.

Activity 1: By February 1, 1995, complete at least two consulting visits, one from Emory SEER group, and one from the Northern California registry, to determine compatibility with different registries.

- Dr. Dee West from California and Dr. Jonathan Liff of Emory consulted with SRRHIS regarding compatibility. $\quad 100 \%$

Activity 2: By March 1, 1995, complete the first comprehensive quality control evaluation of SRRHIS and prepare a report.

- Preliminary drafts of the quality control report have been completed with final report completed by March.

Activity 3: By June 1, 1995, incorporate pathology reports into the routine operations of the registry.

- Contacts have been made with data obtained from most pathologists. Complete incorporation is expected in June. $90 \%$

Activity 4: By June 1, 1995, incorporate death certificates into the routine operations of the registry.

- Agreements with Vital Records authorities have been made. Electronic matching and incorporation is expected by June.100\% 
Activity 5: By June 1, 1995, implement collaborative arrangements with German investigators to establish standard assessment methodology.

- Cancer registry methodology has been reviewed with investigators from Germany (Drs. Bernd Grosche and Mathias Mohner). Plans for further collaboration have been established.

Objective 2: Organize the operations and quality control techniques to assure a high level of data quality.

Activity 1: By December 1, 1994, complete the planning process for an evaluation of SRRHIS.

- The planning process has been established.

Activity 2: By February 1, 1995, complete two quality control site visits, one from Emory (Dr. Jonathan Liff), and one from the Northern California Cancer Center (Dr. Dee West).

- Due in major part to budget cuts, these site visits were not possible. However, phone consultations were completed. $50 \%$

Activity 3: By November 1, 1994, have hospital record and computer data quality control systems in place and functioning.

- Draft of system has been developed with plans for full implementation.

Objective 3: Implement an operations protocol compatible with major (SEER, $\mathrm{ACoS}$ ) surveillance programs.

Activity 1: By March 1, 1995, make the operations manual available to members of North American Association of Central Cancer Registries.

- Manual is completed and is now available.

Activity 2: By June 1, 1995, produce a document describing the unique requirements of a registry which crosses geo-political (state) boundaries.

- Results were presented at the 1994 North American Association of Central Cancer Registries Meeting with plans to publish.

Objective 4: Expand activities seeking to rnake the hospitals and pathology laboratories aware of the benefits of a central cancer registry operation.

Activity 1: By March 1, 1995, conduct at least one workshop for tumor registrars.

- SRRHIS hosted a workshop in January, $1995 . \quad 100 \%$ 
Activity 2: By March 1, 1995, provide technical assistance to all SRRHIS hospitals having their own registries.

- Technical assistance has been provided to most hospitals in the registry. Various detail has been provided. $100 \%$

Activity 3: By March 1, 1995, provide computer software technical assistance to at least one SRRHIS hospital registry.

- Computer technical assistant is actively available, however, the state efforts have reduced this need.

Activity 4: By December 1, 1994, provide each hospital with a confidential report of its cancer cases.

- Comprehensive and individual reports have been provided to hospitals, most of whose cancer committees received private presentations.

Objective 5: Establish and maintain a computerized data management system compatible with major surveillance programs.

Activity 1: By January 1, 1995, produce final documents formalizing the relationship of SRRHIS and the proposed state registry of the S.C. Department of Health and Environmental Control.

- Agreements and relationships have been finalized.

$100 \%$

Activity 2: By January 1, 1995, document the final components and operations of the computer system.

- Drafts have been completed with final document to be completed by June.

Activity 3: By June 1, 1995, distribute the computer operations manual to selected users.

- Plans are being made to announce availability of computer operations manual. It is running behind schedule. $\quad 100 \%$

Activity 4: By June 1, 1995, produce an information brochure describing the computer software system.

- This documentation is for internal use. $100 \%$

Objective 6: Develop a mechanism of collaboration with other registries and information systems.

Activity 1: By March 1, 1995, poll the NAACCR and affiliated registries regarding data sharing and collaborative efforts.

- The activities and plans of the NAACCR negate the need to complete this activity.

Activity 2: By June 1, 1995, develop plan for inter-registry collaboration. - South Carolina inter-agency agreements are completed. $100 \%$ 
Objective 7: Implement a data analysis and reporting system compatible with national and international reporting systems.

Activity 1: By June 1, 1995, add at least two technical reports attributed to SRRHIS.

- Two new technical reports will be completed by June. $\quad 100 \%$

Activity 2: By June 1, 1995, produce at least one peer reviewed journal article with reference to SRRHIS.

- Plans are to submit a manuscript by June. $\quad 50 \%$

Activity 3: By June 1, 1995, document collaborative efforts with a similarly oriented cancer registry in Germany.

- Final collaborative plans will be documented by June. $\quad 100 \%$ (By phone, letter, and get togethers at national or international professional meetings.)

Objective 8: Evaluate the addition of other health-related endpoints to the current surveillance program.

Activity 1: September 1, 1994, discuss the potential value of adding other health endpoints to the cancer and birth defects ones presently in place.

- Additional endpoints are cost prohibitive at this time. $0 \%$

Activity 2: By June 1, 1995, assemble a panel of experts from CDC, ATSDR, DOE, EPA, and selected universities to explore the value and cost of establishing additional outcome variables such as neural, renal, and other body system aberrations.

- Budget cuts prohibited completion of this activity. Agencies expressed interest, but no meeting was held. - $0 \%$

Activity 3: By September 1, 1995, complete a draft of recommendations and circulate them broadly for comment.

- This document will not be completed because of limitations noted above.

$0 \%$

Objective 9: Enhance the influence and recognition of SRRHIS as a resource body in the scientific and lay community.

Activity 1: By March 1, 1995, conduct at least one workshop for tumor registrars.

- A workshop for nearly 50 registrars was held in January. $100 \%$

Activity 2: By July 1, 1995, revise, distribute and print new brochures, and evaluate the number and kinds of requests for them.

- New brochures were designed and printed.

$100 \%$ 
Activity 3: By July 1, 1995, evaluate the quarterly schedule for the routine production of newsletters.

- This activity was evaluated and modified due to cost restrictions.

Activity 4: By July 1, 1995, attend and participate in S.C. and National Tumor Registrars meeting, as well as the meeting of the North American Association of Central Cancer Registrars.

- Both meetings had SRRHIS representation and participation.

GOAL 2: Expand the program to promote community awareness and knowledge of the registry and its benefits.

Objective 1: Maintain and expand the program of resident-oriented communications.

Activity 1: By January 1,1995, refine the existing mailing list to target interested groups in each state.

- List has been drafted and is constantly modified.

Activity 2: By March 1, 1995, prepare and mail a special report on registry purposes, results, and activities to practicing physicians in the SRRHIS area.

- This activity was decreased due to budget reduction. $25 \%$

Activity 3: By June 1, 1995, be a guest on at least two radio talk/interview shows in the SRRHIS area.

- Two radio and two television programs were completed with SRRHIS focus.

Activity 4: By June 1, 1995, appear on at least three community health fairs.

- Budget reduction diminished this activity.

$33 \%$

Objective 2: Evaluate the quality of the community outreach program.

Activity 1: By April 1, 1995, complete an evaluation of the newsletter, community speeches, technical reports, and hospital acceptance of the program.

- This activity will be postponed to Year 05, given budget reduction limitations.

Activity 2: By April 1, 1995, complete an expert review of the entire outreach program, with a report and recommendations from the reviewers.

- This activity will be delayed until Year 05.

$0 \%$

Activity 3. By April 1, 1995, complete a sample telephone survey of SRS residents to ascertain their awareness of the project.

- This activity will be postponed to Year 05. 
Objective 3: Expand the number of community meetings and vary the format to promote better understanding of the registry activities.

Activity 1: By October 1, 1994, hold one meeting of the Steering Committee, with a consultant, to design mechanisms to promote community interest and participation.

- Two consultants met with the Steering Committee regarding community participation.

Activity 2: By November 1, 1994, bring the community lunches program, or other outreach forum, to at least one rural community.

- Community outreach was held in several communities. $100 \%$

GOAL 3: Develop policy and plans for the management and use of SRRHIS data for service, research, and education.

Objective 1: Implement a system of routine data preparation and release regarding results from SRRHIS.

Activity 1: By January 1, 1995, implement a system of hospital reports.

- Hospital reports were designed and distributed.

$100 \%$

Activity 2: By April 1, 1995, at least four presentations will be made to professional organizations, regarding the operations of SRRHIS.

- Presentations were made to nurses, health care administrators, oncologists, urologists, and other groups.

$100 \%$

Objective 2: Develop a detailed policy to govern the release of data for research and other purposes.

Activity 1: By January 1, 1995, convene a group of experts from other registries to help develop a plan for SRRHIS data use in training and research studies.

- Budget reduction has limited this activity. $25 \%$

Activity 2: By March 1, 1995, draft a policy describing the availability of SRRHIS data, and how to apply for it.

- This activity will be completed, but delayed until Year 05. 50\%

Activity 3: By May 1, 1995, disseminate the policy document to potential users of SRRHIS data.

- This document will be distributed in Year $05 . \quad 0 \%$

Objective 3: Implement a training component.

Activity 1: By March 1, 1995, conduct at least one workshop for tumor registrars.

-Workshop was completed in January. 
Activity 2: By April 1, 1995, incorporate SRRHIS into at least one lecture and class curriculum.

- SRRHIS operations are part of "Design and Conduct of Epidemiology Studies."

Activity 3: By April 1, 1995, conduct at least one nationally recognized contemporary education workshop regarding cancer reporting operations.

- Tumor registrars workshop drew a national audience, from 10 states and Puerto Rico.

The goals and objectives are sorted into categories to be emphasized in the second grant period. They are not mutually exclusive. Indeed, there is considerable overlap because specific activities tend to be associated with more than one objective. In many cases we have listed such activities under more than one category, believing the gain in program completeness will make up for the redundancy.

\section{EVALUATION PLAN}

As can be seen from the WORK PLAN above, progress of the program is gauged in two ways, one objective and the other subjective.

1. Objective assessment of the PLAN.

a. Each activity is evaluated based on completion by the planned date. Completion of the task by the planned date equals 100 percent. Ten percent is subtracted for each 30 day delay.

b. Each objective is evaluated by the average score of the activities under it.

c. Progress toward the overall goal is assessed from the average of the objectives
scores.

2. The quality of the technical operations, and the ability to meet the program's other purposes are evaluated by a set of experts brought to the site for review, critique, and
recommendations.

The progress in year 04, judging from the evaluation of the WORK PLAN, was good but not outstanding. We exceeded expectations in the dissemination of information to the residents, and in feed-back to the hospitals. Our pace in collecting data and in scrubbing it has been average, the loss of an abstractor having set us back for several months. But with the arrival of the newly hired abstractor, we anticipate making up any lost time during year 05. Budget limitations caused us to delay bringing consultants for review of our outreach program. Still, it was a very good year and the progress has been solid if not spectacular. 


\section{Note on Use of Carry-Over Funds}

Carry-over funds in the cancer grant program are expected to amount to less than $\$ 14,000$. Our needs for office and newsletter support continue to be substantial because of the large reduction in support in year 04. Further the follow-up poll of residents about their knowledge of this registry program has not yet been completed. For this reason, we ask that any carry-over funds be left with the grant. 


\section{CANCER AND BIRTH DEFECTS SURVEILLANCE SYSTEM FOR COMMUNITIES} AROUND THE SAVANNAH RIVER SITE PHASE I - CANCER

Technical Progress Report Year 04

\section{APPENDICES}




\title{
APPENDIX A
}

\author{
Presentation to the Steering Committee: \\ "Redefining Boundaries of a Geographic Cancer Registry \\ Through Cooperation and Collaboration: SRRHIS" \\ July 14, 1995
}

$\cos x$ 


\section{Redefining Boundaries of a Geographic Cancer Registry Through Cooperation and Collaboration: Savannah River Region Health Information
System}

\section{DANIEL T. LACKLAND*,JONATHAN LIFF, JANIS KOENIG, JOHN
B. DUNBAR}

Medical University of South Carolina, Charleston, SC and Emory
University, Atlanta, GA

Traditional cancer registry operations are ìsually organized along geo-political boundaries. However, cancer cases seldom correspond to these limited bounds. In order to effectively utilize the cancer registry in an assessment such as needed in an environmental hazards investigation, the geographic areas in a population registry must be redefined. The Savannah River Region Health Information System (SRRHIS) was established as a collaborative operation with the Medical University of South Carolina and Emory University to assess cancer incidence in 25 Georgia and South Carolina counties around the Savannah River Site. The cooperation of the two institutions involved shared case ascertainment protocols, data collection and management, staff training, data presentation and quality effectiveness of Such standards and structure are critical to the with simple data sharing. some counties in South Carolina show as great as $20 \%$ is emphasized as diagnosed and treated in Georgia. The uniquat as $20 \%$ of the cancer cases arrangements of SRRHIS are conducive to re structure and collaborative necessary for effective envirenducive to redefinition of geographic areas necessary for effective environmental hazard-human health investigations. 
DE-FG09-91SR18217-4

\title{
APPENDIX B
}

\author{
List of Community and \\ Hospital Outreach Activities
}


cipp. B

\begin{tabular}{|c|c|c|c|}
\hline \multicolumn{4}{|c|}{$\begin{array}{l}\text { SAVANNAH RIVER REGION HEALTH INFORMATION SYSTEM } \\
\text { COMMUNITY AND HOSPITAL OUTREACH EFFORT, YEAR 04 }\end{array}$} \\
\hline Location & Place & $\underline{\text { Date }}$ & Number \\
\hline Orangeburg, SC & $\begin{array}{l}\text { Regional Medical Center of } \\
\text { Orangeburg \& Calhoun Cos. } \\
\text { cancer committee }\end{array}$ & $05 / 19 / 94$ & 2 \\
\hline Blackville, SC & Community leaders & $06 / 16 / 94$ & 4 \\
\hline Hilton Head, SC & $\begin{array}{l}\text { Hilton Head Hospital } \\
\text { cancer committee }\end{array}$ & $07 / 11 / 94$ & 21 \\
\hline Savannah, GA & $\begin{array}{l}\text { Citizens for Environmental } \\
\text { Justice }\end{array}$ & $07 / 22 / 94$ & 6 \\
\hline Barnwell, SC & $\begin{array}{l}\text { Barnwell Memorial Hospital } \\
\text { cancer committee }\end{array}$ & $08 / 18 / 94$ & 6 \\
\hline Johnston, SC & Lion's Club & $08 / 18 / 94$ & 20 \\
\hline Walterboro, SC & $\begin{array}{l}\text { Colleton Regional Hospital } \\
\text { cancer committee }\end{array}$ & $08 / 30 / 94$ & 3 \\
\hline Beaufort, SC & $\begin{array}{l}\text { Beaufort Naval Hospital } \\
\text { hospital medical staff }\end{array}$ & $08 / 30 / 94$ & 2 \\
\hline Aiken, SC & $\begin{array}{l}\text { Aiken Regional Medical Center } \\
\text { cancer committee }\end{array}$ & $08 / 31 / 94$ & 31 \\
\hline Aiken, SC & Aiken Rotary Club & $09 / 19 / 94$ & 101 \\
\hline Orangeburg, SC & $\begin{array}{l}\text { The Regional Medical Center of } \\
\text { Orangeburg \& Calhoun Counties } \\
\text { cancer committee }\end{array}$ & $10 / 20 / 94$ & 7 \\
\hline Beaufort, SC & $\begin{array}{l}\text { Interview on WIWJ, ETV station, } \\
\text { two eight minute segments }\end{array}$ & $11 / 30 / 94$ & TV Audience \\
\hline Aiken, SC & Carpenters' union officials at SRS & $12 / 07 / 94$ & 4 \\
\hline Hilton Head, SC & $\begin{array}{l}\text { TV interview on WHHI-TV, } \\
30 \text { minute segment }\end{array}$ & $12 / 27 / 94$ & TV Audience \\
\hline Barnwell, SC & $\begin{array}{l}\text { Radio Interview on WBAW, } \\
20 \text { minutes }\end{array}$ & $04 / 12 / 95$ & Radio Audience \\
\hline Aiken, SC & $\begin{array}{l}\text { Represent SRRHIS at SRS meeting } \\
\text { about the Cragle worker mortality } \\
\text { study }\end{array}$ & $04 / 21 / 95$ & $50-60$ \\
\hline Blackville, SC & Blackville Country Club reception & $04 / 25 / 95$ & 97 \\
\hline
\end{tabular}


DE-FG09-91SR18217-4

\section{APPENDIX C}

\section{Selected Newspaper Articles}

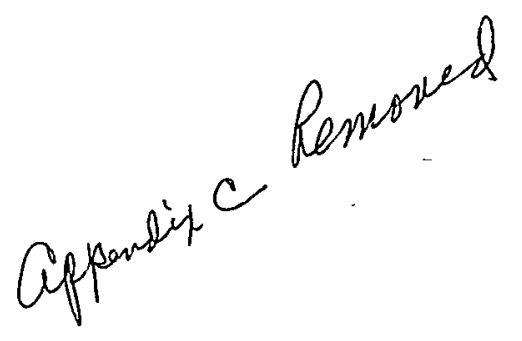




\section{MULTIPLE DATA SOURCES AND EFFECTIVE QUALITY CONTROL IN GEOGRAPHIC CANCER REGISTRY OPERATIONS \\ Lackland DT, Bailey WP, Hudson MB, Corley E, Dunbar JB. Savannah River Region Health Information System (SRRHIS) Medical University of South Carolina}

Cancer prevention programs and trials are dependent on the high quality and accuracy of a population-based registry. Complete ascertainment of cases has traditionally required the expensive - and time-consuming tasks of record review from all hospitals, free-standing clinics and vital records. In an effort to maximize efficiency and quality, SRRHIS has established a collaborative network using hospital discharge, vital records and cancer registry data bases. While nearly $30 \%$ of the cases were initially diagnosed outside the cancer treatment centers, most of these cases were identified in these facilities at the same disease stage as initially diagnosed. These findings identify a potential cost reduction strategy for the operation of a registry and allows the concentration of quality control efforts at the tertiary care levels. These collaborative efforts are a model quality control system for cancer registry operations.

The following are the overheads from the presentation. 


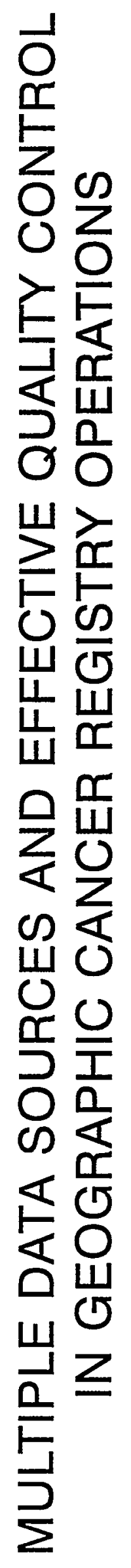




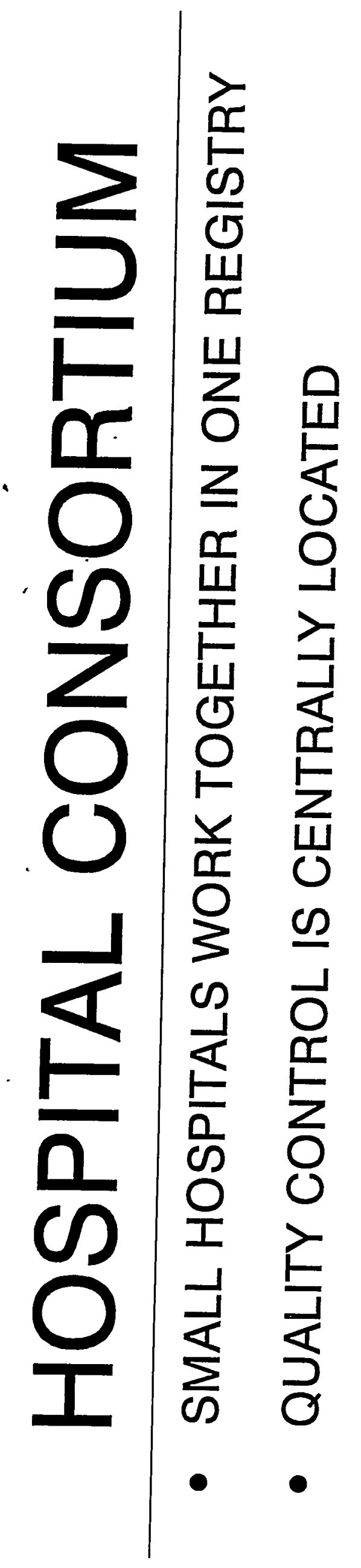




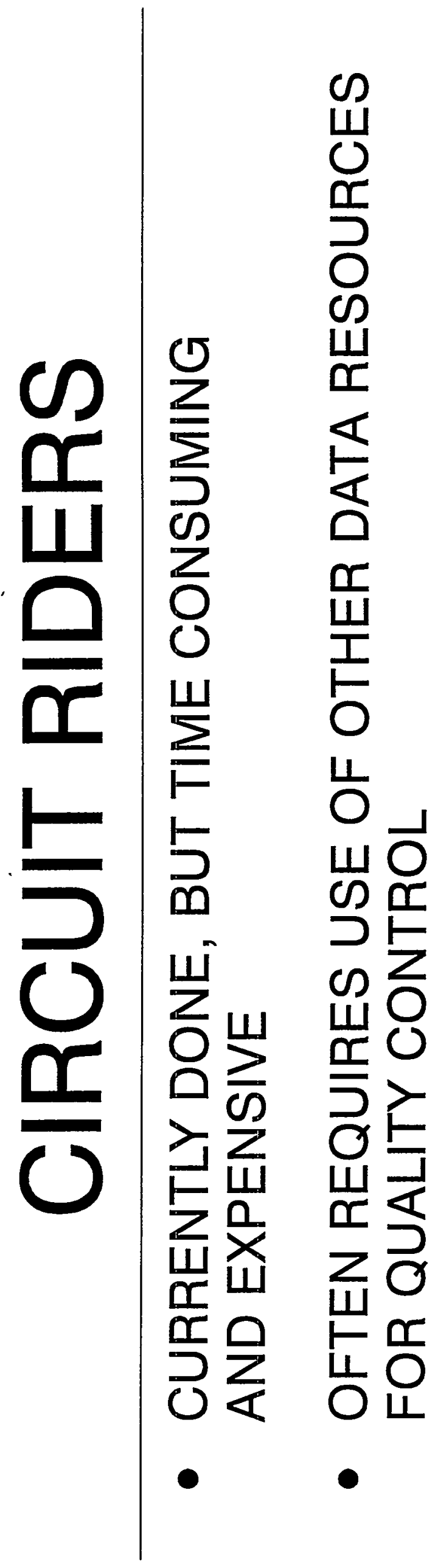




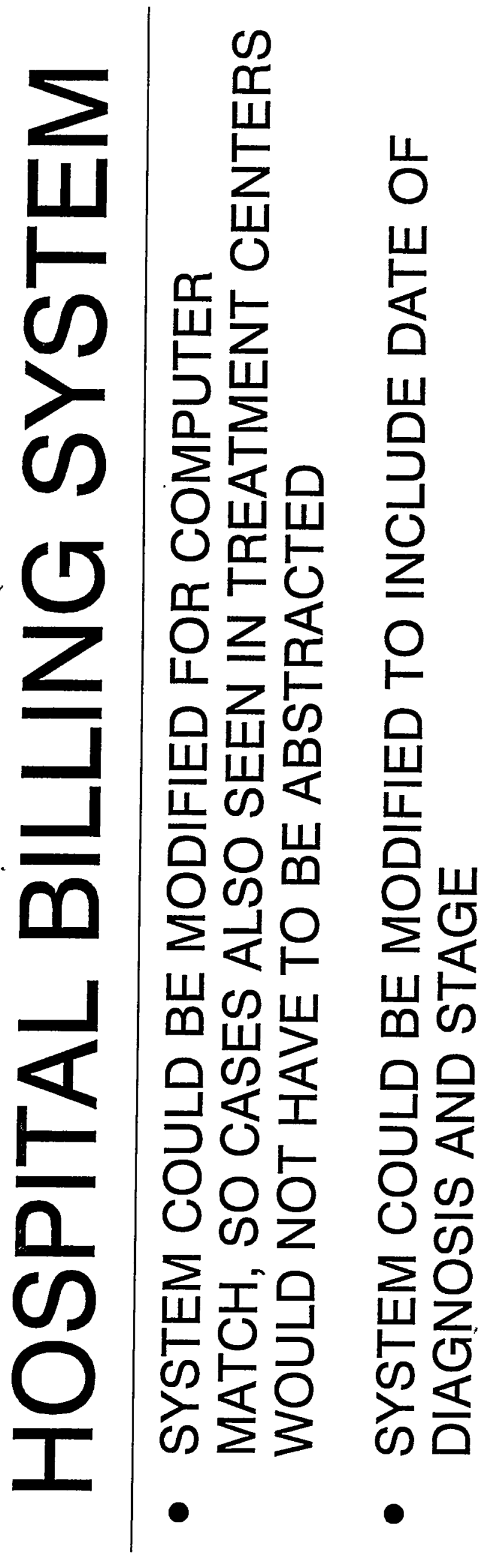




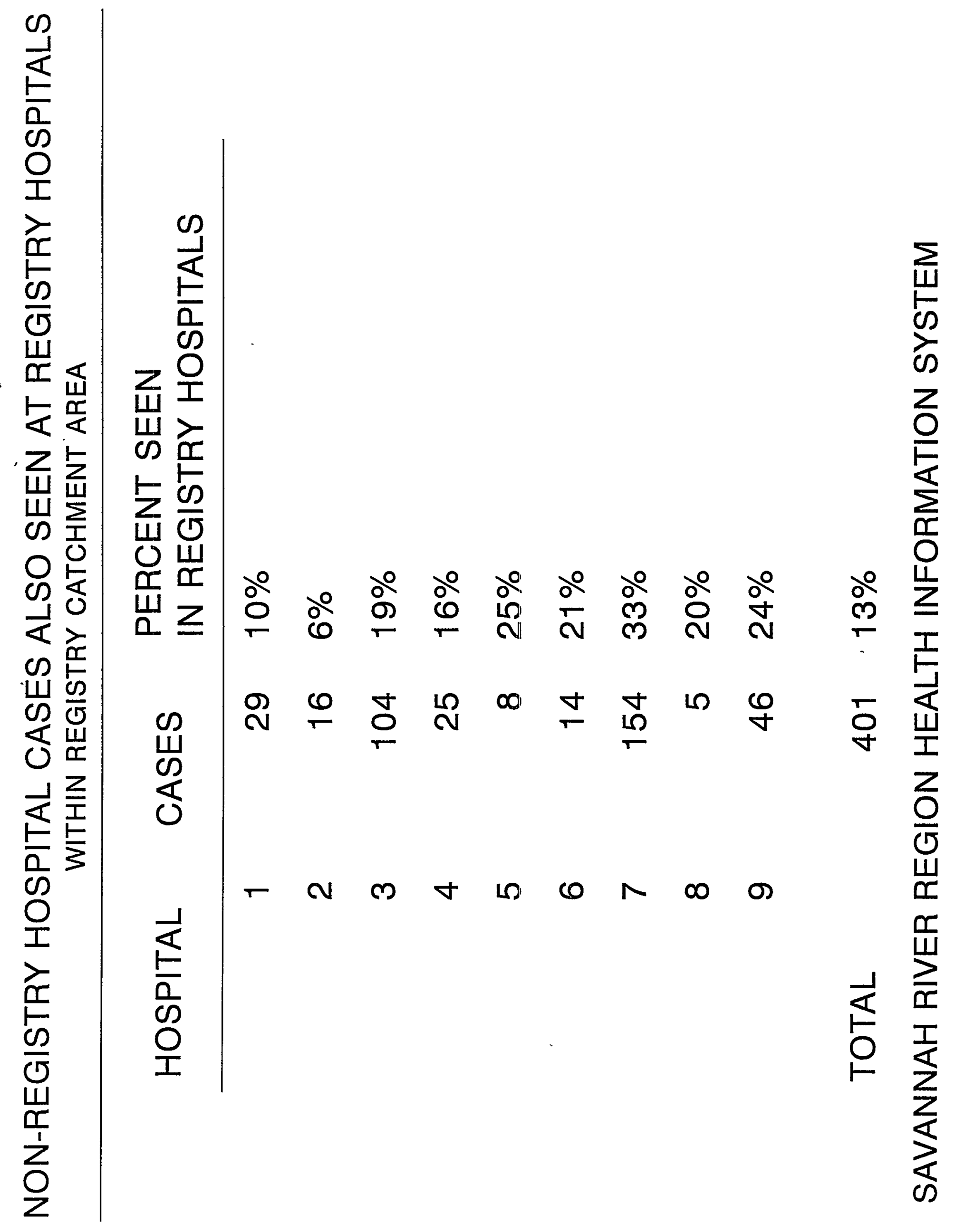




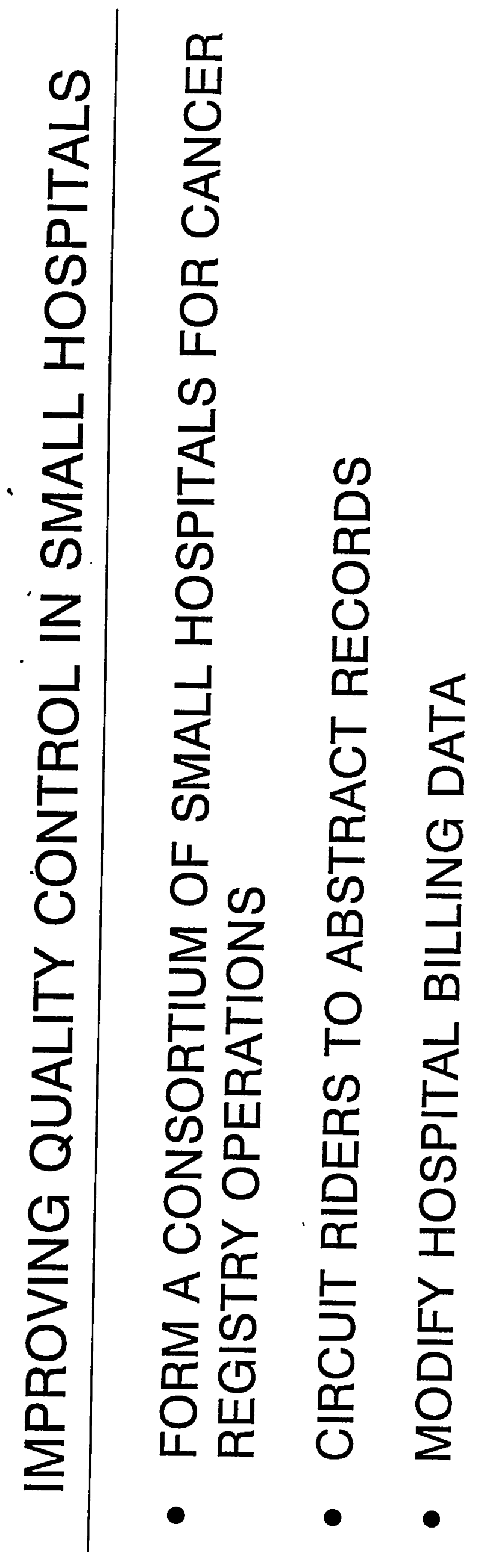




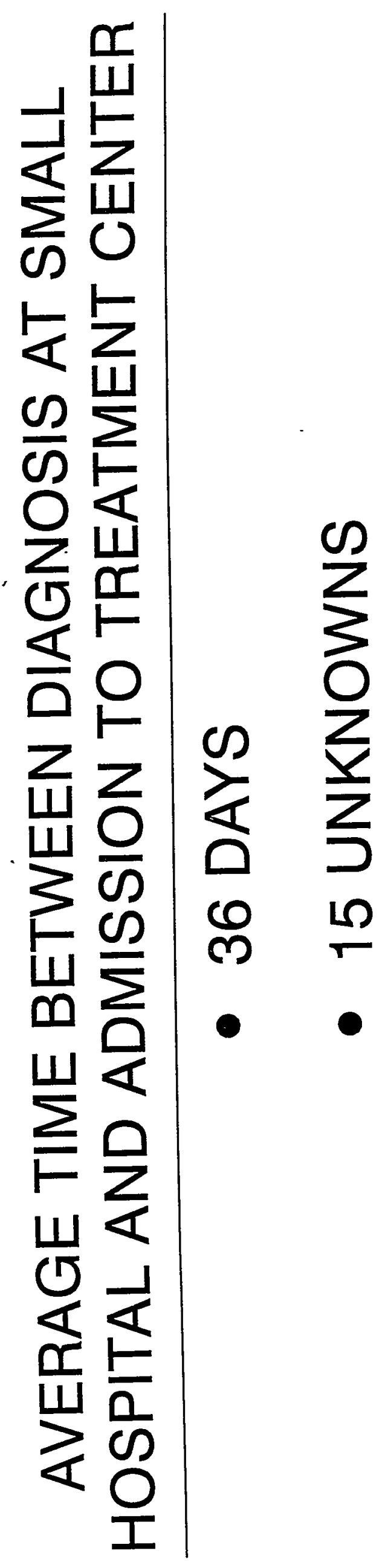




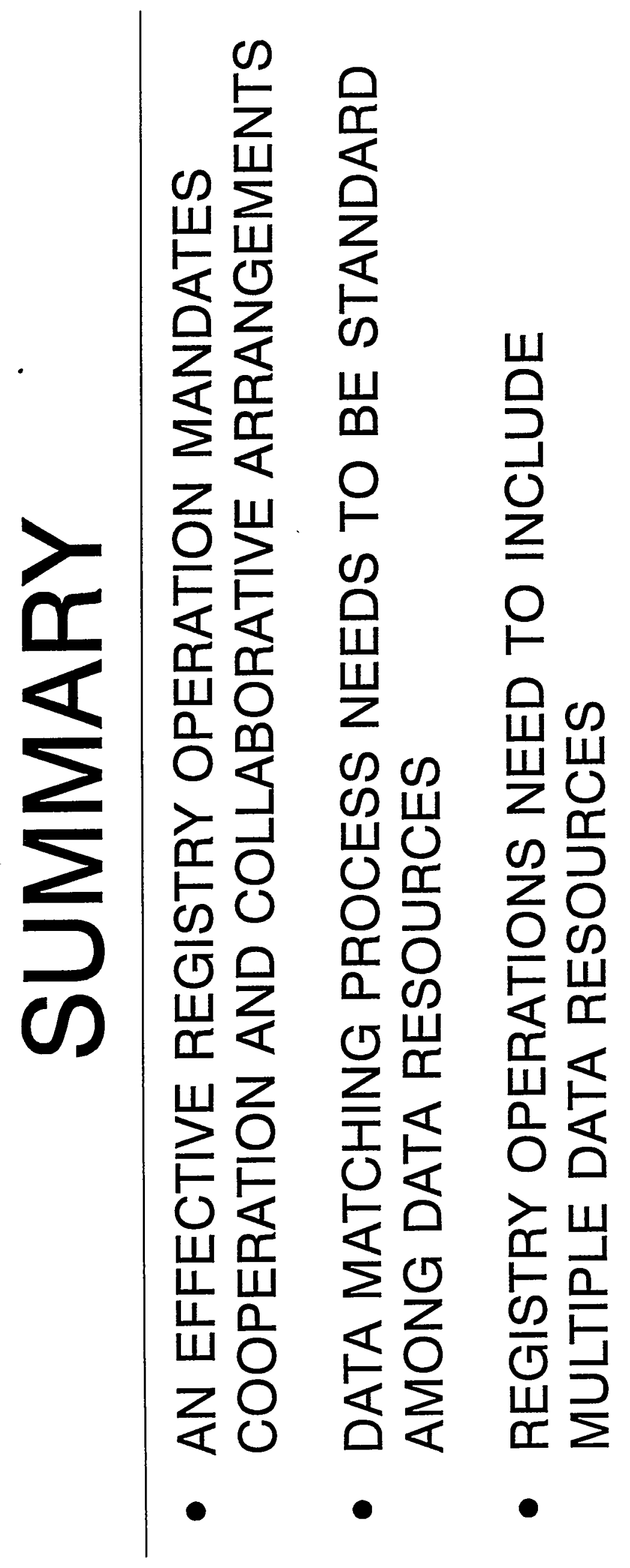




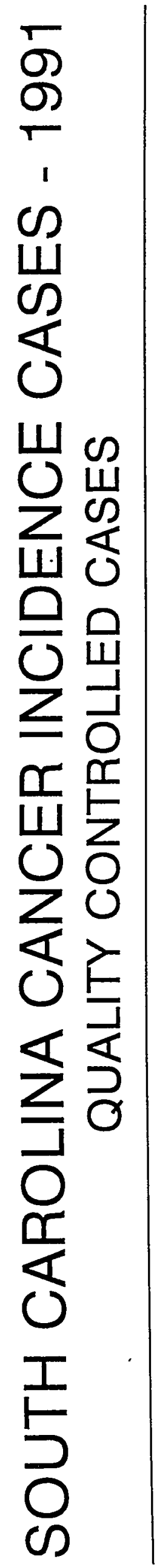

วิ वे oे

1) N

क $ं$ के

Ц

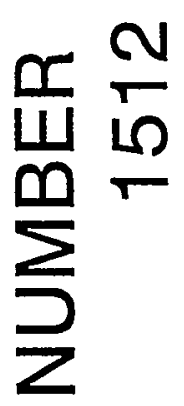

$\begin{array}{lll}+ & \infty & n\end{array}$

$\frac{\sum}{\infty}$

$\frac{Z}{3}$

$\frac{I}{I}$

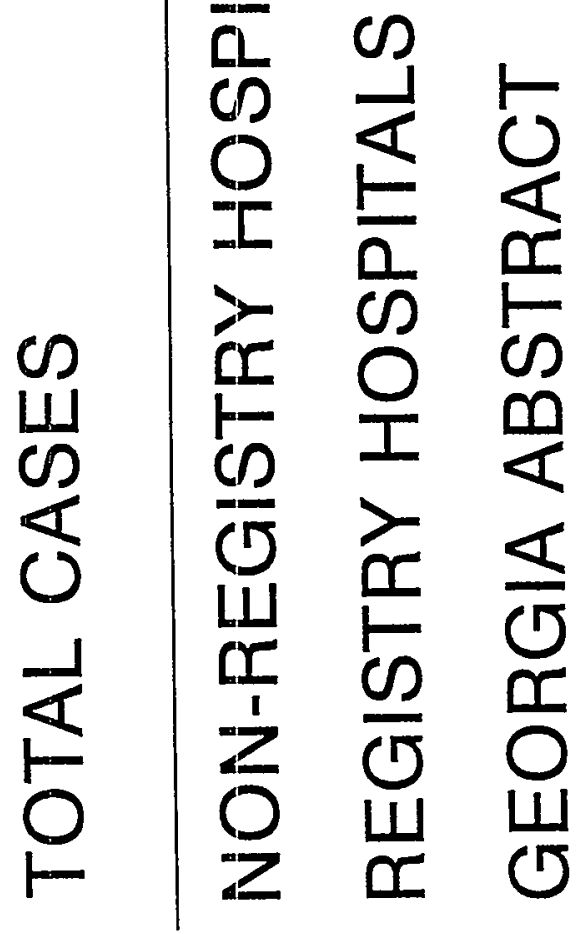




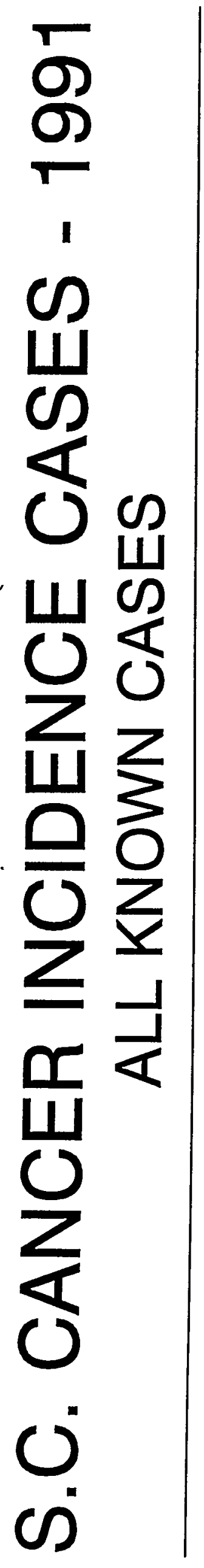

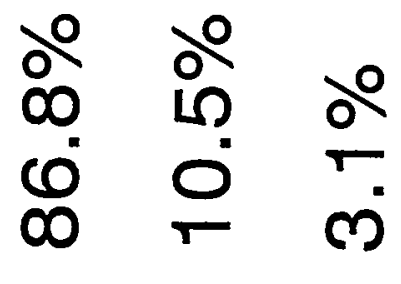

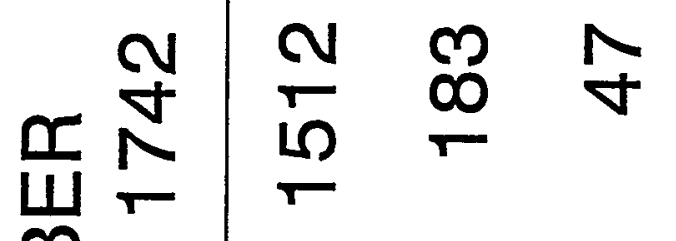

$\sum_{\infty}^{\infty}$

$\sum_{z}^{m}$

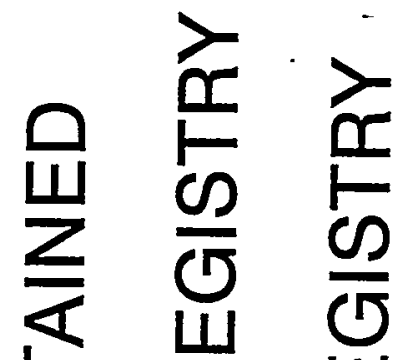

1 崩

뚀 ㄸ

岁 壬

足朵乒

专 至

은

O

$\stackrel{\amalg}{\underline{Z}}$

I

Щ

으

Шّ

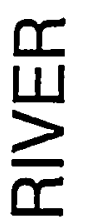

这 


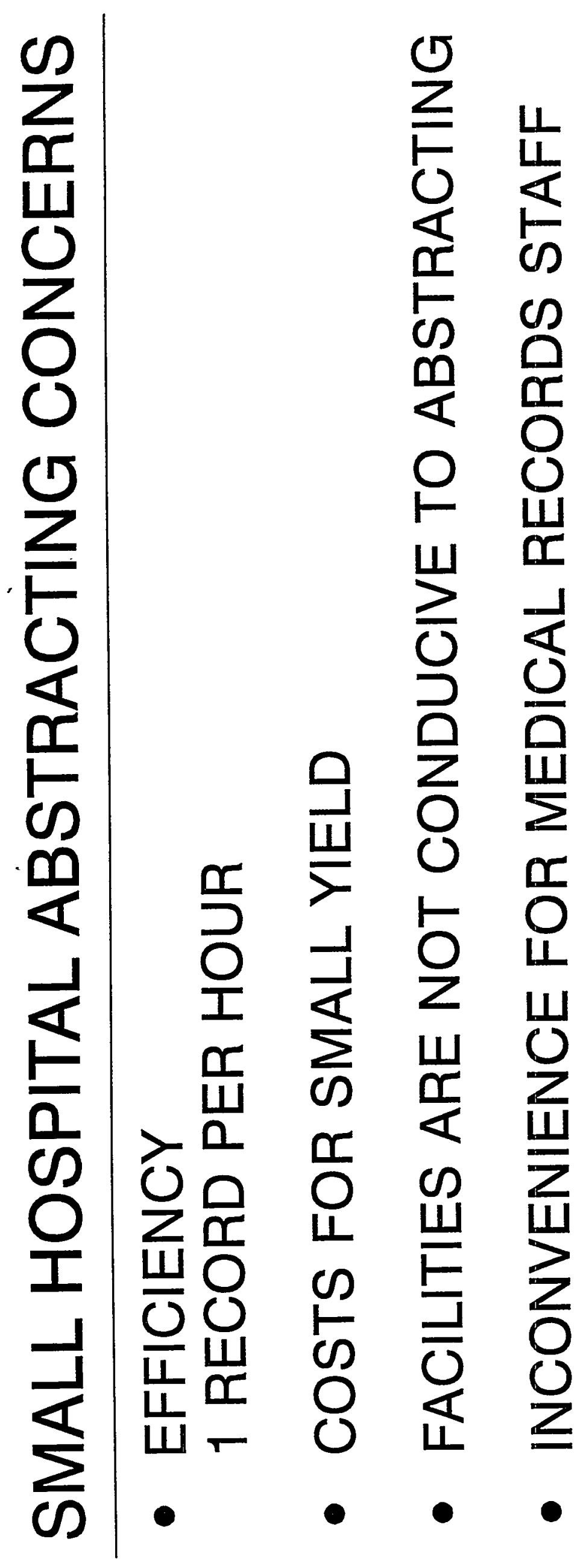




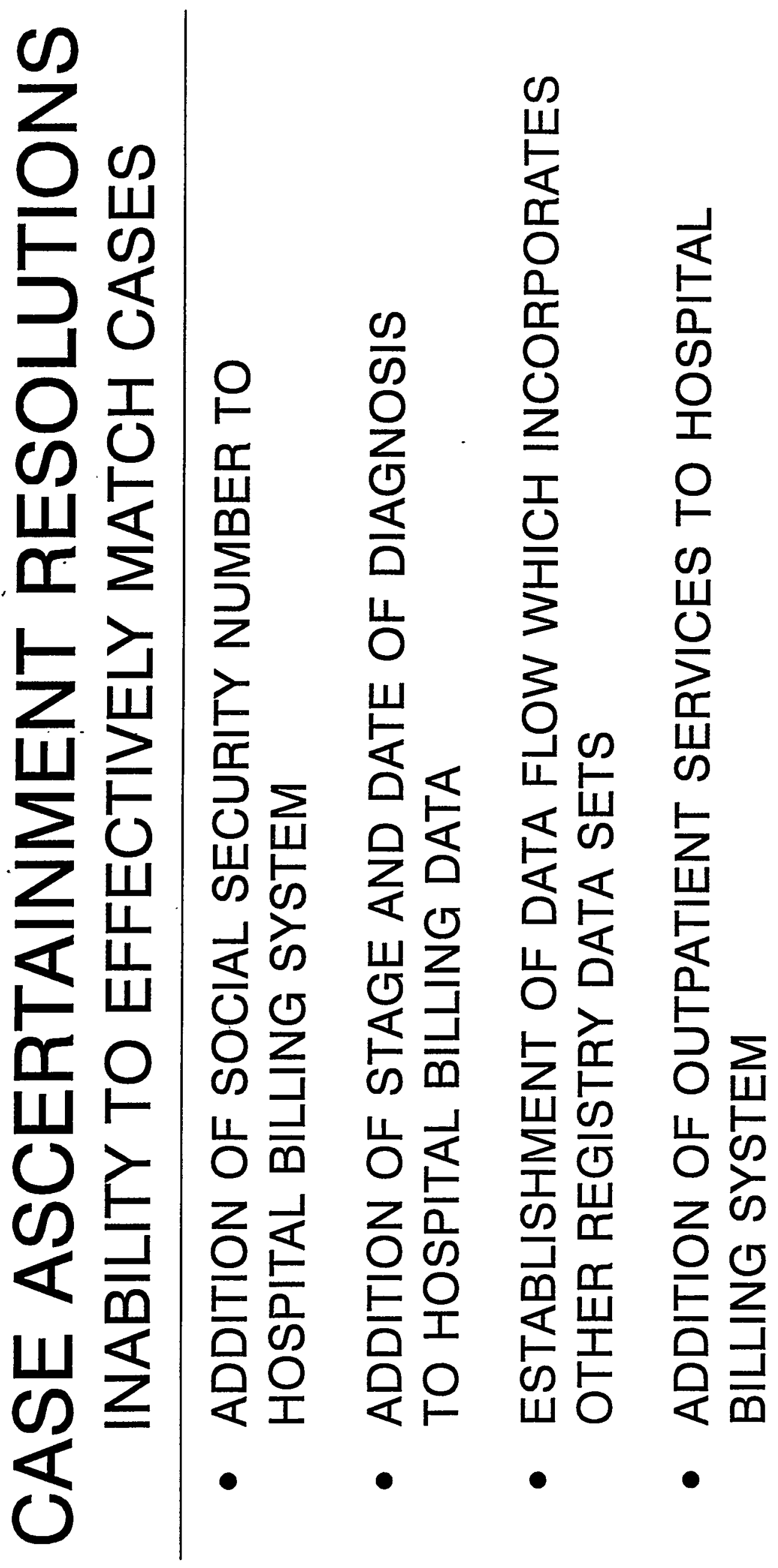




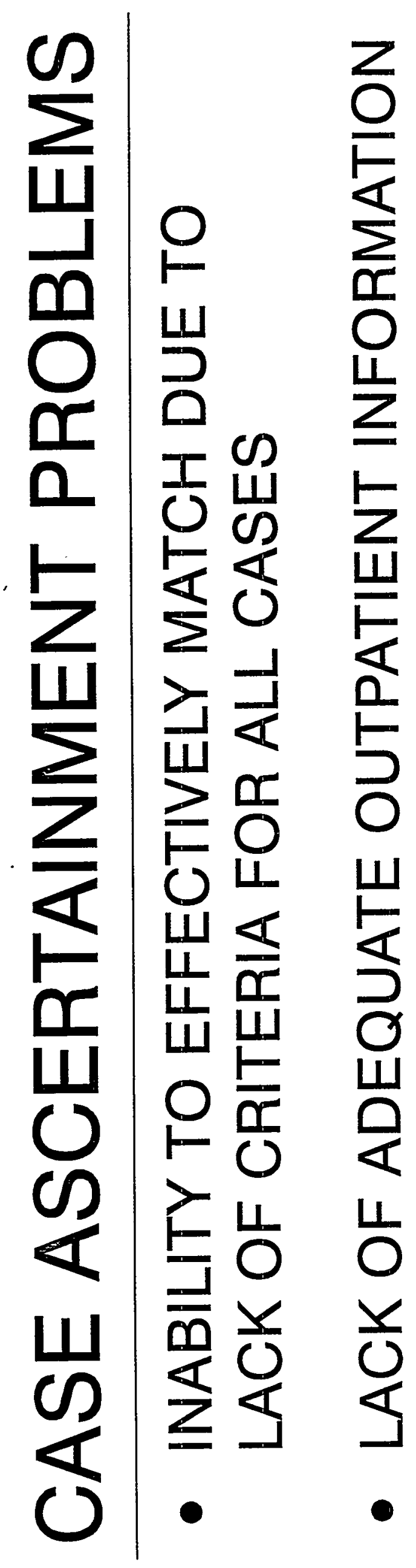




\section{APPENDIX E}

\section{Staff Educational Outreach Activities}




\section{SAVANNAH RIVER REGION HEALTH INFORMATION SYSTEM HEALTH EDUCATION CLASSES AND HEALTH FAIRS}

\begin{tabular}{|c|c|c|c|}
\hline Location & Organization & $\underline{\text { Date }}$ & Number \\
\hline Hampton County, SC & $\begin{array}{l}\text { Presented Mortality Mapping } \\
\text { Program }\end{array}$ & $04 / 94$ & 25 \\
\hline Walterboro, SC & Colleton County Hospital & $05 / 94$ & 100 \\
\hline The Citadel, Charleston, SC & Graduate Class, Health Education & $06 / 14 / 94$ & 28 \\
\hline $\begin{array}{l}\text { Naval Hospital, } \\
\text { Beaufort, SC }\end{array}$ & $\begin{array}{l}\text { Consult about Cancer Registry } \\
\text { Practices }\end{array}$ & $07 / 94$ & 2 \\
\hline Hilton Head Hospital, SC & Tumor Conference-preliminary data & $07 / 94$ & 20 \\
\hline $\begin{array}{l}\text { Charleston Memorial } \\
\text { Hospital, Charleston, SC }\end{array}$ & $\begin{array}{l}\text { Presented "Aims and Purposes of } \\
\text { SRRHIS" }\end{array}$ & $07 / 94$ & 1 \\
\hline $\begin{array}{l}\text { SRRHIS Office, } \\
\text { Charleston, SC }\end{array}$ & $\begin{array}{l}\text { Demonstrate Cansur/Net Data } \\
\text { Management System to visiting } \\
\text { professors from China }\end{array}$ & $08 / 94$ & 3 \\
\hline $\begin{array}{l}\text { Trident Regional Medical } \\
\text { Center, Charleston, SC }\end{array}$ & $\begin{array}{l}\text { Participated in Prostate/Skin Cancer } \\
\text { Screening }\end{array}$ & $10 / 94$ & 300 \\
\hline $\begin{array}{l}\text { VA Medical Center, } \\
\text { Charleston, SC }\end{array}$ & $\begin{array}{l}\text { Administration and Medical Records } \\
\text { Staff-preliminary data }\end{array}$ & $11 / 94$ & 5 \\
\hline $\begin{array}{l}\text { SRRHIS Office, } \\
\text { Charleston, SC }\end{array}$ & $\begin{array}{l}\text { Director, Disease Monitoring and } \\
\text { Control Division, Department Health, } \\
\text { Savannah, GA - cancer data }\end{array}$ & $11 / 94$ & 3 \\
\hline $\begin{array}{l}\text { SRRHIS Office, } \\
\text { Charleston, SC }\end{array}$ & $\begin{array}{l}\text { Representative from CDC-SRRHIS } \\
\text { role in the State Registry }\end{array}$ & $12 / 94$ & 5 \\
\hline Charleston, SC & $\begin{array}{l}\text { SRRHIS/SCCCR Training Program } \\
\text { Presentation "Quality Control and } \\
\text { Assurance" }\end{array}$ & $01 / 95$ & $\begin{array}{l}80 \\
46\end{array}$ \\
\hline $\begin{array}{l}\text { MUSC Health Information } \\
\text { Management class, } \\
\text { Charleston, SC }\end{array}$ & $\begin{array}{l}\text { "Cancer Registrar as a Professional } \\
\text { in the Health Care Field" }\end{array}$ & $02 / 95$ & 15 \\
\hline $\begin{array}{l}\text { CHP, Room 311, MUSC, } \\
\text { Charleston, SC }\end{array}$ & $\begin{array}{l}\text { Junior Students, College of Health } \\
\text { Information, MUSC }\end{array}$ & $02 / 23 / 95$ & 21 \\
\hline $\begin{array}{l}\text { SRRHIS Office, } \\
\text { Charleston, SC }\end{array}$ & $\begin{array}{l}\text { Steering Committee member- } \\
\text { demonstrate SRRHIS data collection } \\
\text { management system }\end{array}$ & 03/95 & 1 \\
\hline MUSC, Charleston, SC & $\begin{array}{l}\text { Charleston Heart Study-Cancer } \\
\text { Correlation Study - Validation } \\
\text { Consultant }\end{array}$ & $04 / 95$ & 5 \\
\hline
\end{tabular}


cases annually. It will be of interest to both the lay and medical communities to determine how many and what kind of defects occur in the area.

Data Collection: The criteria for including new births in the SRRHIS BDR file are: (1) the mother's residence at the time of birth is in one of the 25 SRRHIS counties, (2) the child must have a structural or genetic birth defect of interest to the registry, (3) the defect must be diagnosed within the first year of the child's life, (4) the infant/fetus must have a gestational age of at least 20 weeks or a birth weight of at least 500 grams. Relevant birth defects data will be collected prospectively as well as retrospectively, as far back as 1990 if feasible.

Since SRRHIS BDR aims for $100 \%$ ascertainment of selected birth defects, a trained case abstractor actively seeks and screens information on birth defect cases from the obstetric and pediatric logs and medical records of the cooperating hospitals, laboratories, and clinics.

The data are entered directly into a laptop computer as they are abstracted. They are uploaded into the relational database from which statistical and progress reports are produced. Quality control methods are similar to those of the SRRHIS Cancer Registry. The SRRHIS Quality Control Editor periodically visits the hospitals, proceeds with the screening of the logs, reabstracts from the medical records from randomly chosen suspected cases, and evaluates the information against what is in the BDR database. Furthermore, a clinical genetics consultant participates in semi-annual review of the cases to confirm diagnoses.

Confidentiality: Personal and hospital identification information is collected strictly for the purpose of eliminating duplication of cases and of linking to vital statistics records to augment demographic and diagnostic information. Any data files released to users other than SRRHIS staff are stripped of personal and hospital identifiers. 
The SRRHIS Birth Defects Registry

Purpose: The purpose of the Savannah River Region Health Information System Birth Defects Registry (SRRHIS BDR) project is to establish an intensive ascertainment system to monitor selected birth defects among babies born to the residents of 25 Georgia and South Carolina counties which are adjacent to and downstream from the Savannah River Site (SRS). The SRRHIS BDR will be modeled after the Metropolitan Atlanta Congenital Defects Program (MACDP) of the Center for Disease Control and Prevention (CDC) which has actively monitored the incidence of birth defects in the Metropolitan Atlanta area since 1967. SRRHIS BDR began in the fall of 1994, at which time funding support was provided by the U.S. Department of Energy.

Background: Concerns have been expressed by the residents of the SRRHIS communities about the potential teratogenic effect of ionizing radiation. The perception is that birth defects may be resulting from radioactive materials released into the air and water. There are other sources of toxic substances, but low dose radiation from SRS appears to be the source of greatest public concern.

Since neither South Carolina nor Georgia requires the reporting of birth defects, the major source of birth defects incidence data is the birth certificate. Like many passive systems of surveillance, the birth certificate greatly underestimates the number of birth defects, mainly because many defects are undetected or misdiagnosed at birth. The SRRHIS BDR will improve the identification and recording of these defects and make possible comparisons with data from other regions and states.

Approximately 31,000 live births were recorded in the SRRHIS counties in 1990. Assuming a 3 to $4 \%$ occurrence rate of major birth defects, one can expect to observe about 1,000

\section{SAVANNAH RIVER REGION HEALTH INFORMATION SYSTEM Steering Committee Members}

Ms. Mildred Ford, Chairwoman Blackville, South Carolina

Ms. Susan W. Bolick

Columbia, South Carolina

Dr. William Irby

Statesboro, Georgia

Ms. Linda James

Augusta, Georgia

Dr. Stephen King

Savannah, Georgia

Mr. Dean Moss

Beaufort, South Carolina

Ms. Anne Nevils

Blackville, South Carolina

Mr. Robert Parker

Sylvania, Georgia

Mr. Andrew Rea

Savannah, Georgia

Mr. James Undertilo

Aikën, South Carolina

Ms. Brenda Williams

Orangeburg, South Carolina

Mr. Barry Fountos

Department of Energy Representative Washington, D.C. 


\section{5 \\ Goals of Savannah River Region HEALTH INFORMATION SYSTEM}

- Assembling and reporting estimates of cancer incidence (new cases) in the 25 contiguous counties ( 13 in South Carolina and 12 in Georgia).

- Monitoring cancer incidence in the SRRHIS region, so as to identify unusual changes occurring in population subgroups defined by geographic, demographic, and social characteristics.

- Evaluating the effects of overall cancer control efforts by examining information on changes over time in the amount of cancers of specific types, and in the extent of disease at the time of diagnosis.

- Passive follow-up of patients through death record surveillance to determine survival by type of cancer.

- Promoting dissemination of registry findings to public health authorities, health practitioners, and the residents of the region.

- Promoting research to identify factors related to cancer control such as:

a) environmental, social, dietary, occupational;

b) early detection and treatment;

c) determinants of length of patients' survival and their quality of life.

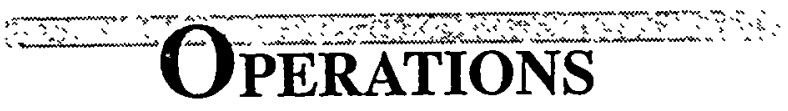

The Registry collects incidence data and general cancer staging codes at diagnosis. No treatment data or follow-up is collected. Data is entered directly into a computerized cancer registry data management system.

The SRRHIS faculty and staff wish to establish a model registry and to make its resources available to cooperating facilities. SRRHIS staff are prepared to answer any questions concerning the Registry, coding, software, or hardware. Further, training will be provided upon request for medical records or cancer registry personnel in cooperating facilities. The SRRHIS faculty and staff include experts in tumor registry software and computer programming.

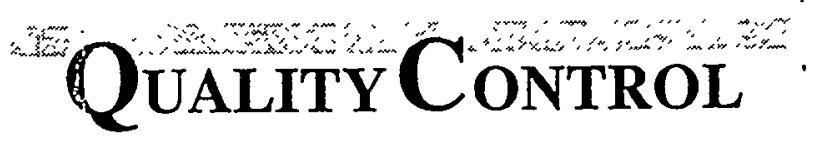

Quality of the data submitted to SRRHIS is a major concern. Data is edited by staff and computer review. The edit procedures identify such discrepancies as duplicate records, invalid codes, incorrect gendercancer site combinations. Quality control visits to each hospital in the registry are routinely conducted to assess the completeness of the data and accuracy of the reports. In addition, SRRHIS hosts workshops and training programs for local registries, and provides individual consultations.

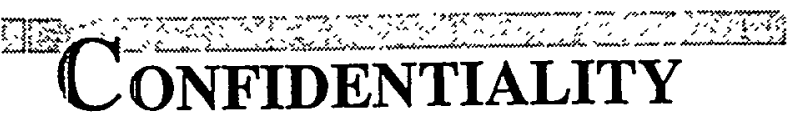

SRIRHIS confidentiality policy is designed to protect the privacy of patients, physicians, and facilities participating in the project. This is accomplished in the following ways:

- Access to computer data is restricted to registry personnel.

- All data and forms are maintained in secure compartments.

- All facility and personal identifying information is kept secure at all times.

- $A$ confidentiality form is signed by all registry staff upon employment. 


\section{INTRODUCTION}

In recent years, the nation's and South Carolina's health care industry has been particularly responsive to public concern about cancer. To a significant extent, this public concern translates into public support because research findings have made prevention and early detection of some cancers into realizable goals. Further, modern state-of-the-art treatment can extend lives of those with cancer. One has only to read the papers, turn on the television, or visit local hospitals and academic medical centers to recognize the pace at which health care institutions and professionals are responding to cancer control.

To guide this growing effort, and to evaluate its success in future years, a way was needed to measure the amount and kinds of cancer in a given geographic area, and to determine the associated risks for the area's residents. The use of mortality records was considered. However, mortality records, while they indicate the general impact of cancer on a community, provide information that is only supplementary to the more direct and reliable method of cancer incidence. This is also because death records underestimate those cancers which are associated with long patient survival times. With improving cancer treatment, more cancer patients are living longer, more useful lives. An incidence registry is the most efficient and precise way to measure cancer occurrence, and the magnitude of a cancer problem in a given population.

An incidence registry collects all newly diagnosed cancer cases from hospitals and pathology laboratories pertaining to residents of a defined geographic area within a specified time period. With such a registry, one can record accurately the numbers and kinds of cancers occurring in residents by sex, age, race, and other demographic and health characteristics. From registry data the rise or fall of incidence of specific cancers can be observed. This information permits the follow-up effor success of cancer detection and to healthy living styles (such as non-smolic's response healthy diet).

\section{History}

The Epidemiology faculty of the Medical University of South Carolina (MUSC) Department of Biometry and Epidemiology decided in the middle to late 1980s to assess the feasibility of developing a cancer registry in the Tri-County area. It was recognized that the success of the effort would depend on the cooperation of individual hospitals and laboratories. The State of South Carolina has never required the reporting of cancer cases. The nine Charleston area acute care hospitals, including the two Federal hospitals (Veterans Administration and U.S. Navy) were contacted early in 1990 about their willingness to participate in this registry program.

The cancer registry was named the Tri-County Central Cancer Registry of South Carolina (TCCRSC) and began collecting information from the area hospitals in the summer and fall of 1990. All cancers newly diagnosed on or after January 1, 1990 were included in the Registry. The Registry was accepted into membership of the American Association of Central Cancer
Registries in 1990.

Also in 1990, the Epidemiology faculty, in collaboration with the faculty of Emory University School of Public Health, submitted a grant application to the U.S. Department of Energy (DOE). It proposed to develop a cancer registry incorporating counties within 50 miles of the Savannah River Site (SRS) and those downstream to Beaufort and Savannah. The Emory University faculty already had a state-of-the-art SEER (Surveillance, Epidemiology, and End Results) cancer registry supported by the National Cancer Institute. The DOE approved the proposal and funded it for three years, beginning April 29, 1991. The project was titled the "Savannah River Region Health Information System (SRRHIS)." A renewal application, submitted in 1992 for an additional three years of support, was awarded on April 30, 1994. This will support the project through April 29, 1997. 


\section{$=$ \\ Savannah River Region}

For further information regarding the

Savannah River Region Health Information System

(SRRHIS), please write or call:

Ms. Janis S. Koenig, M.Ed.

Project Administrator

Savannah River Region Health Information System

401 Harborview Office Tower

Medical University of South Carolina

171 Ashley Avenue

Charleston, SC 29425-2503

Telephone: (803) 792-4081 Fax: (803) 792-3180
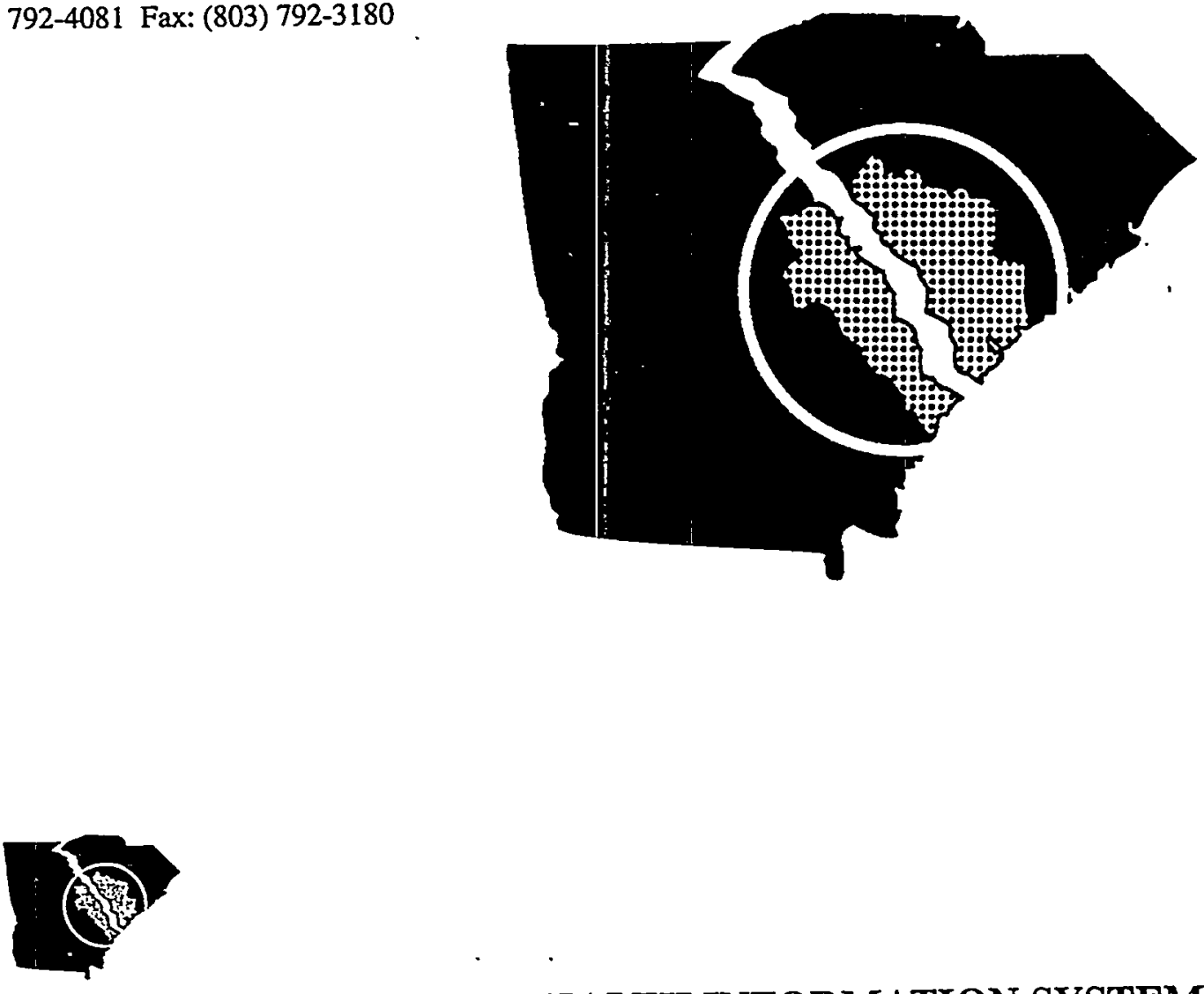

Stremail fiver Rogion Heath informamon Systom

HEALTH INFORMATION SYSTEM 


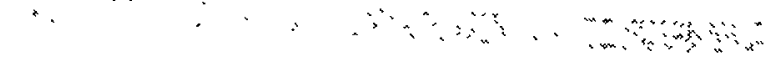

Susan Pater, ART, CTR, is the Field Cancer Abstractor of the South Carolina component of the Savannah River Region Health Information System (SRRHIS).

Margery Swanson is the Project Secretary of the South Carolina component of the Savannah River Region Health Information System (SRRHIS).

\section{SRRHIS - GEORGIA STAFF
EMORY UNIVERSITY} Epidemiology in the Emory University School of Public Health, and serves as Principal Investigator of the Georgia component of the Savannah River Region Health Information System (SRRHIS).

Nancy D. Ferrelle, CTR, is the Quality Control Coordinator of the Georgia component of the Savannah River Region Health Information System (SRRHIS).

Kenneth A. Gerlach, M.P.H., is the Project Administrator of the Georgia component of the Savannah River Region Health Information System (SRRHIS).

Helen Gregory, ART, is the Quality Control Editor of the Georgia component of the Savannah River Region Health Information System (SRRHIS).

May Ting Liu, M.P.H., is the Data Analyst for the Georgia component of the Savannah River Region Health Information System (SRRHIS).

Beverly Richards, CTR, is the Field Cancer Abstractor of the Georgia component of the Savannah River Region Health Information System (SRRHIS).

Lina Steele is the Senior Systems Analyst for the Georgia component of the Savannah River Region Health Information System (SRRHIS).

\section{PARTICIPANT REPORTING AREAS}

GEORGIA

SOUTH CAROLINA
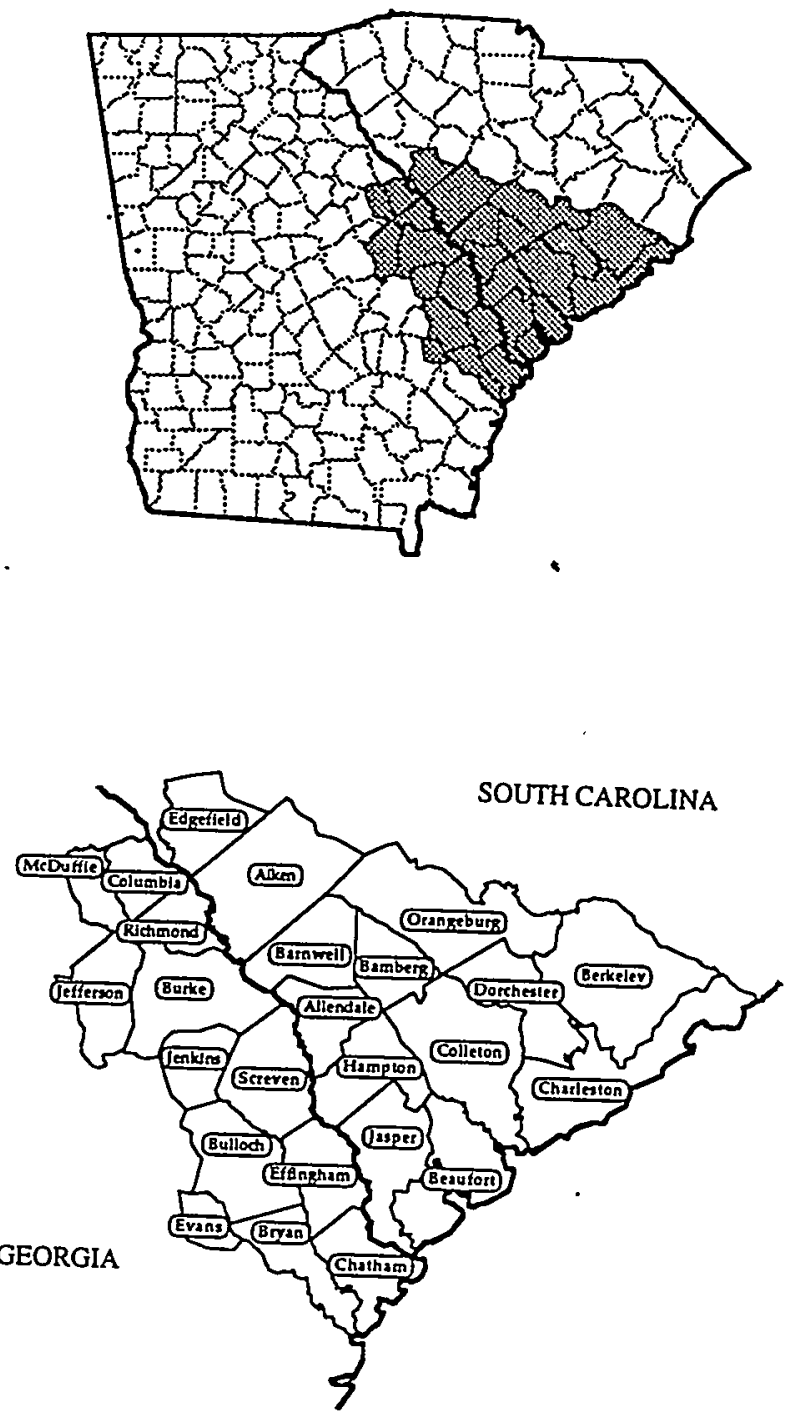

The SRRHIS reporting area provides populationbased information for all counties within 50 miles of the Savannah River Site as well as those downstream to Beaufort and Savannah. Other selected distant counties will serve as comparison areas. 
DE-FG09-91SR18217-4

\section{APPENDIX G}

\section{Savannah River Region Health Information System Brochure}




\section{APPENDDX G}

\section{Savannah River Region Health Information System Brochure}




\section{FACULTY/SPEAKERS}

Marshall Austin, M.D., Ph.D., Head, Microbiology Department, Staff Pathologist, Roper Hospital, and SRRHIS Physician Advisor, Charleston, SC

Susain Bollck, MSPH, CTR, Cancer Registry Administrator, Central Cancer Registry, South Carolina Department of Health and Environmental Control, Columbia, SC

Helen M. Dodds, M.D., Assistant Chief of Pathology. and Laboratory Medicine Service at Ralph H. Johnson Department of Veteran Affairs Miedical Center, Charleston, SC

Janis S. Koenig, M.Ed., Project Administrator, and Training Programs Coordinator, Savannah River Region Health Înformation System, Medical

John S. Metcalf, M.D., Associate Professor of Pathology and Laboratory Medicine; Director of :Surgical Pathology, Medical University of South Carolina, Charleston, SC

Susan Radovich, CTR, Training Analyst, Cancer Patient Data Program, Department of Eidemiology and Biostatistics, University of Califomia, San Francisco; Regional Cancer Program Consultant, American College of Surgeons

Zarrin Navvab, MS, Statistician, Research and Training, Cancer Patient Data Program, Department of Epidemiology and Biostatistics, University of California, San Francisco 


\section{SCHEDULE FOR CTR EXAMINATION REVIEW WORKSHOP}

\section{Session 1}

\section{Saturday,January 7 HOTEL LOBBY \\ -EVENING}

5:00 - 7:00 p.m. Early Registration

Sunday.January 8

\section{TRUE LAUREL ROOM \\ -MORNING}

7:30 - 8:00 a.m. Registration

8:00 - 8:15 a.m. Welcome Susan Bolick, MSPH, CTR, Cancer Registry Administrator, SC DHEC and Janis Koenig, M.Ed, Project Administrator, SRRHIS, Medical University of SC, Charleston

8:15 - 8:45 a.m. Introduction/Workshop Overview Susan Radovich, CTR, Research and Training, University of Califormia, San Francisco 8:45 - 10:15 a.m. Computer Technology Zarrin Navvab, MS, Research and Training, University of Califormia, San Francisco

10:15 - 10:30 a.m. Break

10:30 - 11:15 a.m:-Medlcal Records Review Susan Radovich, CTR

11:15 - 12:30 p.m. American College of Surgeons Approvals Program

.Susan Radovich, CTR

-AFTERNOON.

12:30 - 1:30 p.m. Lunch (on your own)

1:30 - 2:45 p.m. Statstics and Epidemiology

Zarrin Navvab, MS

2:45 - 3:00 p.m. Break

3:00 - 4:30 p.m. Statistics and Epidemiology (continued)

Zarrin Navvab, MS
Monday.January 9

TRUELAUREL ROOM

-MORNING .

8:00 - 8:15 a.m. Welcome/Introduction

..: $\quad$ Susan Bolick, MSPH, CTR and

Janis Koenig, M. Ed.

8:15 - 9:30 a.m. Anatomy Review

$\therefore \quad$ Marshall Austin, M.D., Ph.D., Head, Microbiology Department, Staff Pathologist, Roper

$\therefore$ Hospital, and SRRHIS Physician Advisor,

Charleston, $S C$

9:30 - 10:30 a.m. Anatomy Exercises

$\therefore$ Susan Radovich, CTR

10:30 - 10:45 am. Break

50:45- 12:00 noon Common Neoplasms/Dlagnostic

W Procedures

in. John S. Metcalf, M.D., Associate Professor of

Pathology and Laboratory Medicine;

Director of Surgical Pathology, Medical

He University of SC, Chairleston

AFTERNOON

$12: 00$ - 1:00 p.m. Lunch (on your own)

1:00 - 2:15 p.m. Histological Classification

Hi.. Helen M. Dodds, M.D., Assistant Chief of

- Lethology and Labooratory Medicine Service

at Ralph H. Johnsón Departiment of Veteran

It) Affairs Medical Center, Chärlestor, SC

2:15 - 2:30 p.m. Break .

2:30 - 4:30 p.m. Coding, Staging, and Abstracting

Review

Susan Radovichi, CTR

Susan Radouichi, CTR , ...

4:30 - 5:00 p.m. Question and Answer Sesșion/

. Discussion 


\section{GENERAL INEORMATION}

Hotel Registration:

Participants should contact Hawthorn Suites Hotel directly at 1-800-527-1133 to reserve a room. When calling, indicate you will participate in the CTR Examination Review Workshop to receive the special rate of .. \$93.50 for single/double occupancy (includes tax, daily breakfast buffet, and daily wine and cheese social). Current on-site daily parking is $\$ 6.00$ for registered guests and others on a first come/first serve basis. The suites are spacious and for anyone wishing to share a room; a "roommate list" will be

- maintained at SRRHIS. Call Charlene Seltz for further information (803) 792-0331. Hotel room blocks are reserved until December 9, 1994.

Registration Fee: $\$ 150.00 \div$ The fee includes the seminar manual "Certi-" fied Tumor Registrar Examination Preparation Manual", self-assessment materials, and all breaks. Program limited to 50 participants. Please make checks payable to: SCATR - CTR Examination Review Workshop.

What to Bring with You:

- Cancer Program Manual, American College of Surgeons Commission on Cancer, 1991.

- International Classification of Disease for Oncology (ICD-O), Second Edition, World Health Organization, Geneva.

- Manual for Staging of Cancer, Fourth Edition. American Joint Committee on Cancer (AJCC), 1992.

- Summary Staging Guide, Surveillance,

- Epidemiology and End Results (SEER) Program, NIH Publications (or SEER SelfInstructional Book 6).

- Calculator.

Continuing Education Units: Endorsed by National Cancer Registrars Association, Inc. (NCRA). This program has been submitted to NCRA for continuing education credit. Certificates will be issued.
CTR EXAMINATION REVIEW WORKSHOP

Cancer Patient Data Program Research and Training. University of Callfornia San Francisco

San Francisco, Callfornia

$$
\text { sponsored by }
$$

The Savannah River Region Health Information System

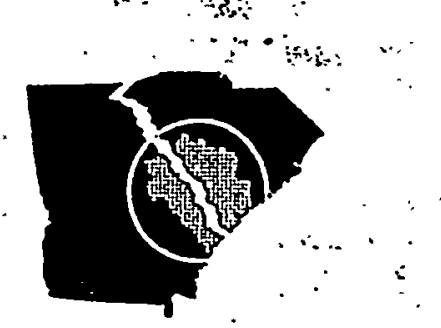

and

The South Carolina Central Cancer Registry

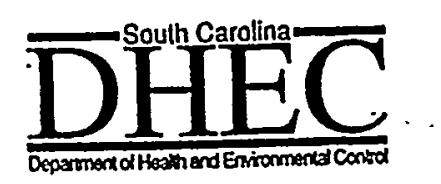

Sunday and Monday January 8 \& 9, 1995

Hawthorn Suites Hotel at the Market Charleston, South Carolina 


\section{CTR EXAMINATION REVIEW WORKSHOP Charleston, South Carolina January 8 \& 9, 1995}

This workshop is intended to assess the $\because .$. cancer registrars' knowledge of cancer, registry theory and practice prior to the National Cancer Registrars Association's Certified Tumor Registrar (C.T.R.) Certification Examination.

This review workshop will consist of lectures by experienced program staff, intermixed * with exercises and discussion.

\section{WORKSHOP OBJECTIVES:} At the end of the workshop, participants , should be able to:

$\therefore$ assess areas of strengths and weaknesses in cancer registry theory and practice.

- identify areas requiring concentrated study prior to the examination date. FOR CANCER REGISTRARS TEST DATES:

March 18, 1995

September 16, 1995

PLEASE NOTE: SRRHISISCCCR make no guarantee that registrants who attend this review workshop will pass the Certification Examination.

For further information contact Janis Koenig, M.Ed. (803) 792-4081 


\section{FACULTYISPEAKERS}

Susan Bolick, MSPH, CTR, Cancer Registry Administrator, Central Cancer Registry, South Carolina Department of Health and Environmental Control, Columbia, SC

Fletcher C. Derrick, Jr., MD, Clinical Professor of Urology, Medical University of South Carolina, Charleston, $\mathrm{SC}$ - also in private practice

Charles D. Graham, MD., Board Certified, Hematology-Oncology. In private practice with Robert Silgals, MD, at The Cancer Center, Trident Regional Medical Center

Janis S. Koenig, M.Ed., Project Administrator, and Training Programs Coordinator, Savannah River Region Health Information System, Medical University of South Carolina, Charleston, SC

Susan Radovich, CTR, Training Analyst, Cancer Patient Data Program, Department of Epidemiology and Biostatistics, University of California, San Francisco; Regional Cancer Program Consultant, American College of Surgeons

Carolyn E. Reed, MD, Associate Professor of Cardiothoracic Surgery, Medical University of South Carolina, Charleston, SC

Charlene Seltz, CTR, Quality Control Editor, Savannah River Region Health Information System, Medical University of SC, Charleston, SC; President of SC Association of Tumor Registrars

Elizabeth Wingate, $\mathrm{MD}$, in private practice with Urology Offices of Raymond Rosenblum, MD; Fletcher C. Derrick, Jr., MD; Ian Y. Marshall, MD; and Elizabeth Wingate, $\mathrm{MD}$ 


\section{SCHEDULE FOR ADVANCED CANCER REGISTRY TRAINING PROGRAM}

iession 2

Monday,January 9

-EVENING - HOTEL LOBBY

6:00 - 8:00 p.m. Early Registration

Tuesday, January 10

-Morning - TRUE LAUREL ROOM

8:00 - 9:00 a.m. Registration

9:00 - 9:15 a.m. Welcome \& Introduction Susan Bolick, MSPH, CTR, Cancer Registry

Administrator, SC DHEC and Janis Koenig,

M.Ed., Project Administrator, SRRHIS,

Medical University of SC, Charleston

9:15 - 10:15 a.m. Current Issues in the Diagnosis, Staging, and Treatment of Prostate Cancer

Fletcher C. Derrick, Jr., MD, Clinical

Professor of Urology, Medical University of

$S C$, Charleston - also in private practice

10:15 - 10:30 a.m. Break

10:30 - 12:15 p.m. Workshop on Prostate Cancer

Susan Radovich, CTR, Research \& Training,

University of California, San Francisco

-AFTERNOON

12:15 - 1:15 p.m. Lunch (on your own)

1:15 - 2:15 p.m. Diagnosis, Staging, and Treatment of Bladder Cancer

Elizabeth Wingate, $M D$, in private practice with Urology Offices of Rosenblum, Derrick, Marshall and Wingate

2:15 - 2:30 p.m. Break

2:30 - 4:30 p.m. Workshop on Bladder Cancer

Susan Radovich, CTR

5:30 - 7:00 p.m. Reception - COURTYARD

Wednesday,January 11

-Morning - TRUE LAUREL ROOM

8:00 - 8:15 a.m. Session Overview

8:15 - 9:45 a.m. Determination of Multiple Primary

Cancers

Susan Radovich, CTR

9:45 - 10:45 a.m. Diagnosis, Staging, and Treatment of Lung Cancer

Carolyn E. Reed, MD, Associate Professor of Cardiothoracic Surgery, Medical University
10:45 - 12:30 p.m. Lung Cancer Workshop Susan Radovich, CTR

-AFTERNOON

FREE TIME

-EVENING

6:30 - 7:00 p.m. Use of Cancer Registry Data

Susan Bolick, MSPH, CTR

7:00 - 9:00 p.m. Promote Your Registry; Read and Evaluate Medical Literature; Helpful Hints - Annual Reports

Susan Radovich, CTR

Thursday January 12

-Morning - TRUE LAUREL ROOM

8:45 - 9:00 a.m. Session Overview

9:00 - 10:15 a.m. Diagnosis, Staging, and Treatment of Lymphomas

Charles D. Graham, $M D$, in private practice at $t$ The Cancer Center, Trident Regional Medical Center

10:15 - 10:30 a.m. Break

10:30 - 12:30 p.m. Lymphoma Workshop

$\therefore$ Susan Radovich, CTR

AFTERNOON

12:30 - 1:30 p.m. Lunch (on your own)

1:30 - 2:30 p.m. Quality Control Workshop

Charlene Seltz CTR, Quality Control Editor,

$\because \quad$ SRRHIS Cancer Registry, Medical University

$\because \quad$ of SC, Charleston, SC

2:30- 2:45 p.m. Break

2:45 - 5:30 p.m. Quality Control Workshop

$\therefore \quad$ (continued)

Charlene Seliz, CTR

Friday January 13

-Morning - AKEBI ROOM

8:00 - 8:15 a.m. Session Overview

8:15 - 10:15 a.m. Problem Areas for Registrars Susan Bolick, MSPH, CTR; Susan Radovich,

$\because \quad$ CTR; and Charlene Seltz, CTR

10:15 - 10:30 a.m. Break

10:30 - 11:30 a.m. Final Question and Answer Period - Certificates of Completion, Evaluation and Closing 


\section{GENERAL INFORMATION}

Hotel Registration:

Participants should contact Hawthorn Suites Hotel directly at 1-800-527-1133 to reserve a room. When calling, indicate you will participate in the Advanced Cancer Registry Training Program to receive the special rate of $\$ 93.50$ for single/double occupancy (includes tax, daily breakfast buffet, and daily wine and cheese social). Current onsite daily parking is $\$ 6.00$ for registered guests and others on a first come/first serve basis. The suites are spacious and for anyone wishing to share a room, a "roommate list" will be maintained at SRRHIS. Call Charlene Seltz for further information (803) 792-0331. Hotel room blocks are reserved until December 9, 1994.

Registration Fee: $\$ 200.00$ The fee includes the program materials, an evening social, and all breaks. Program limited to 50 participants. Please make checks payable to: SCATR - Advanced Cancer Registry Training Program.

What to Bring with You:

- Cancer Program Manual, American College of Surgeons Commission on Cancer. 1991.

- International Classification of Disease for Oncology (ICD-O), Second Edition, World Health Organization, Geneva.

- Manual for Staging of Cancer, Eourth Edition. American Joint Committee on Cancer (AJCC), 1992.

- Summary Staging Guide, Surveillance, Epidemiology and End Results (SEER) Program, NIH Publications (or SEER SelfInstructional Book 6).

- Calculator-required. Annual Report optional.

Continuing Education Units: Endorsed by National Cancer Registrars Association, Inc. (NCRA). This program has been submitted to NCRA for continuing education credit. Certificates will be issued.
ADVANCED CANCER REGISTRY TRAINING PROGRAM

\author{
Cancer Patient Data Program - \\ Research and Training \\ University of Callfornia \\ San Francisco \\ San Francisco, Callfornia
}

sponsored by

\section{The Savannah River Region Heaith Information System}

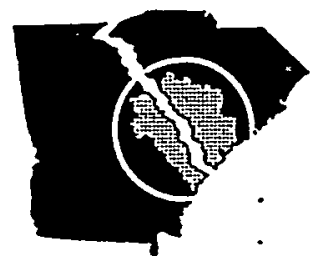

and

The South Carolina Central Cancer Registry

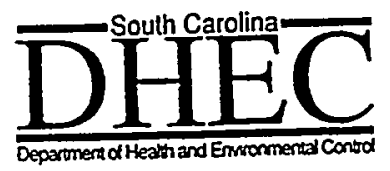

January $10-13,1995$

Hawthorn Suites Hotel at the Market Charleston, South Carolina 


\section{ADVANCED CANCER REGISTRY TRAINING PROGRAM \\ Charleston, South Carolina January 10 - 13, 1995}

This program provides a short intensive overview of hospital registry operations. Participants will gain practical experience as well as a perspective on current developments in the field. Abstracting, TNM staging, and ICD. -2 coding of medical information will be practiced during the workshop. The program is designed for the intermediate/ advanced cancer data manager.

WORKSHOP OBJECTIVES: At the end of the workshop, participants should be able to:

- identify problems in determining multiple primary vs. single site cancers and record pertinent diagnostic techniques.

- improve the quality of coded primary sites and histologic types of cancer according to the International Classification of Diseases for Oncology Second Edition.

- utilize the latest methodology to determine extent of disease and assign the correct SEER extent of disease codes, summary stage, and AJCC (TNM) stage of cancer.

- recognize common problems in defining the "first course of treatment," identify and code required treatment information.

- recognize the benefits of good quality control and perform the latest techniques necessary to insure the integrity of the data.

For further information contact Janis Koenig, M.Ed. (803) 792-4081 


\title{
APPENDIX H
}

\author{
CTR Examination Review Workshop \\ and \\ Advanced Cancer Registry Training Program \\ Brochures
}




\section{SAVANNAH RIVER REGION HEALTH INFORMATION SYSTEM}

\section{STEERING COMMITTEE}

1. Ms. Susan W. Bolick, MSPH, CTR Cancer Registry Administrator SC DHEC

2600 Bull Street

Columbia, SC 29201

Telephone: 803-734-4683

FAX: 803-734-5131

2. Ms. Mildred Ford, Chair 707 North Solomon Blatt Avenue Blackville, SC 29817

Telephone: 803-284-2196

3. Ms. Linda James

Biology Department

Paine College

1235 - 15th Street

Augusta, GA 30910

Telephone: 706-821-8203

4. William Irby, Ph.D.

Deparment of Biology

Georgia Southern University

Landrum Box 8042

Statesboro, GA 30460-8042

Telephone: 912-681-0076

Fax: 912-681-0845

5. Stephen King, M.D.

Director Eastern Health District

P. O. Box 14257

Savannah, GA 31416-1257

Telephone: $912-356-2441$

FAX: 912-356-2868

6. Mr. Dean Moss

General Manager

Beaufort-Jasper Water/Sewer Authority

P.O. Box 2149

Beaufort, SC 29901

Telephone: 803-521-9200

FAX: 803-521-9203
7. Ms. Anne M. Nevils

305 N. Lartique Street

Blackville, SC 29817-1329

Telephone: 803-284-2442

8. Mr. Ronald Parker

4575 Millen Highway

Sylvania, GA 30467

Telephone: 912-863-7731

9. Mr. Andrew Rea

55 East Deerwood Road, Apt. 17

Savannah, GA 31410

Telephone: (hm) 912-898-1233

10. Mr. James Joseph Undertilo

610 Redds Branch Road

Aiken, SC 29801

Telephone: wk: 803-641-4747

Telephone: hm: 803-649-3377

11. Ms. Brenda L.Williams

Vice President

The Regional Medical Center of

Orangeburg \& Calhoun Counties

3000 St. Matthews Road

Orangeburg, SC 29115-1498

Telephone: 803-533-2461

DOE Mr. Barry Fountos

EH-62/270 CC

U.S. Department of Energy

19901 Germantown Road

Germantown, MD 20874-1290

Telephone: 301-903-6740

FAX: 301-903-4677 
DE-FG09-91SR18217-4

\title{
APPEND][X I
}

\author{
Steering Committee Members \\ and \\ Steering Committee By-Laws
}


January 1994

\title{
BYLAWS OF \\ THE SAVANNAH RIVER REGION HEALTH INFORMATION SYSTEM STEERING COMMITTEE
}

\begin{abstract}
ARTICLE I.
Name and Office

Section 1. The name of the Committee shall be the Savannah River Region Health Information System Steering Committee (SRRHIS Steering Committee). The office shall be located at the Medical University of South Carolina in Charleston, South
Carolina.

ARTICLE II

Purpose
\end{abstract}

The purposes of the Steering Committee are:

(a) To assist SRRHIS and the Department of Energy in designing and developing the Savannah River area cancer and birth defects registries, and in making knowledge of them and their findings widely available to the public.

(b) To advise, counsel and make recommendations to the SRRHIS Project Director, whether for technical matters or those involving broader issues of public understanding and information availability.

\section{ARTICLE III \\ Membership}

Section 1. The Steering Committee shall consist of twelve (12) voting members and one permanent non-voting member of the Department of Energy, but in the event of a vacancy, the Committee may act with a lesser number until such vacancy is filled.

Section 2. Qualifications for membership shall include:

(a) Persons who live and have interest in the Savannah River Region.

(b) Professional and technical experts with skills relevant to the Project.

An attempt shall be made to elect members so as to represent Georgia, South Carolina and different parts of the region more or less equally over the long term. 
Section 3. Terms of appointment for each voting Committee member shall be for three (3) years. The first Steering Committee shall be appointed to staggered memberships of one (1), two (2), and three (3) year terms. Thereafter, all appointees shall serve three years . with one-third being replaced or reelected each year. A voting Committee member shall serve no more than two consecutive three year terms. After a lapse of two or more years, a Committee member may be reelected.

Section 4. Nominations for election to the Steering Committee shall be submitted in writing to the Committee at the regular Committee meeting in October. All Committee members shall be encouraged to submit names of nominees upon receiving consent from the nominee. Nominations also may be accepted from the floor with the consent of the nominee. Elections will be held each year at the regular Committee meeting in October. Each member of the Committee shall be entitled to one vote for each vacancy to be filled. A quorum of the Committee must be present at the time of election.

Section 5. Vacancies on the Steering Committee shall exist upon the death, resignation, expiration of term or Committee removal of any voting Committee member. A voting member of the Steering Committee may resign at any time. The resignation shall take effect upon receipt of a letter of resignation or on the date specified therein. A person shall be elected member of the Steering Committee by a quorum of the Committee to fill any unexpired term.

\section{ARTICLE IV}

\section{Officers}

Section 1. The officers of the Steering Committee shall consist of a Chairperson, Vice Chairperson, Secretary, and such other officers as the Steering Committee may authorize.

Section 2. The duties of the officers of the Steering Committee shall include but not be limited to the following:

(a) The Chairperson shall preside over all Committee meetings and shall be kept advised of the general affairs of the SRRHIS Project. He/She shall be an exofficio member of all committees.

(b) The Vice Chairperson shall have full authority to act for the Chairperson in his/her absence or incapacity.

(c) The Secretary shall ensure that any actions taken are followed up, shall record the minutes of all meetings, and notify all Committee members of regular meetings.

Section 3. Elections of officers shall be held by the Steering Committee each year in January. All officers shall be elected for a term of one year and shall be members of the Committee, except for the Secretary who, at the discretion of the Steering Committee, may be a staff person. No member may hold the same office more than two consecutive years. 


\section{ARTICLE V}

\section{Meetings}

Section 1. The Steering Committee shall meet quarterly. The location of each meeting and time shall be established by the Committee. All meetings will use Roberts Rules of

Section 2. Special meetings of the Steering Committee may be called any time by the Chairperson, Vice Chairperson, SRRHIS Project Director, or by two Committee members. All special meetings must have a specified agenda and be called for a special purpose. Section 3. At all meetings a quorum shall consist of one-half plus one of the voting
Committee members. Section 4. A majority of voting Committee members present at any meeting shall decide
all matters voted upon.

Section 5. A Committee member may use a proxy to represent him/her at meetings. A proxy may not vote or be used as an attendance for the absent Committee member.

\section{ARTICLE VI}

Committees

The Steering Committee may from time to time create standing or ad hoc committees with such duties and powers as the Steering Committee may prescribe.

\section{ARTICLE VII \\ Removal of Committee Members}

Section 1. Committee members are expected to attend all regular and special meetings. A Steering Committee member shall be removed following two consecutive unattended meetings. That member may be reinstated if, at his or her request, the Committee passes,

Section 2. A voting Committee member may be removed for any reason by the Steering Committee when the Committee determines that such action is in the best interest of the members. 


\section{ARTICLE VIII}

Expenses

While attending the meetings of the Steering Committee each member of the Steering Committee shall be reimbursed for travel expenses, in accordance with the South Carolina State Budget and Control Board policy.

\section{ARTICLE IX}

\section{Amendments}

These Bylaws may be amended by a two-thirds vote of all voting Committee members at any regular meeting, provided the proposed amendment was presented at the previous meeting and has been submitted to the Committee members in final form, in writing, at least thirty (30) days prior to date of contemplated action. 
DE-FG09-91SR18217-4

\section{APPENDIX J'}

\section{Emory University Technical Report \\ Grant Year 04}




\title{
Savannah River Region Health Information System
}

\author{
Georgia Section (Emory University)
}

\section{CONTRACT PROGRESS REPORT - May 24, 1995}

During the past year, the Savannah River Region Health Information System (SRRHIS) has continued the collection of 1992 through 1994 cancer cases in the 12 Georgia SRRHIS counties. The collection of cancer incidence data occurred in several forms: from data submitted on electronic media (diskettes) by selected hospital tumor registries, and from the Augusta-bașed SRRHIS Field Coordinator who collected data from hospitals and free-standing laboratories on a laptop microcomputer software program. In addition, abstractors were hired on a parttime and temporary basis, in Savannah, to collect information from free-standing pathology and radiation treatment facilities, collect information in the Savannah hospitals on outpatients not followed by the hospital cancer registrars, and collect data from one hospital whose registry is not functioning well.

The SRRHIS data entry system and relational database have continued to be modified. Computerized edits were installed on both the laptop and desktop versions, reducing the amount of visual editing. We have continued to work with hospital tumor registry computer software vendors and their Georgia clients to assure that submitted data conform to national standards. Quality control has been carried out, and we have continued to streamline the collection, flow, and analysis. of data.

Death clearance is the evaluation to determine whether individuals who were reported on their death certificates to have died of cancer, but were not included in the cancer registry, should have been included. We reported last year that due to budget cuts we would be unable to perform death clearance. Nevertheless, we have included the 1991 cancer deaths on the edit data-base, and will be assessing the cost involved in completing this task.

The following indicate the project goals and objectives, and the progress on these that have been completed in the past year. Following them are tables summarizing the data collected as of March 1995. 


\section{SAVANNAH RIVER REGION HEALTH INFORMATION SYSTEM (SRRHIS)-GEORGIA ANNUAL PROGRESS REPORT - MAY 24, 1995}

GOAL 1: Maintain and improve the state-of-the-art health information system.

Objective 1: Implement a system of cancer surveillance with case ascertainment such that comparison with other internationally recognized systems is
fostered.

Progress Information on all eligible Georgia or South Carolina SRRHIS area residents diagnosed with cancer between 1991 and 1993 has been abstracted or received from 56 hospitals, pathology laboratories, or outpatient treatment centers. The single exception is a hospital in Savannah, where completeness of data by the hospital cancer registry was determined to be inadequate, and where data collection continues. As of March, 1995, 8,699 records for 8,210 patients diagnosed in these years were obtained. In addition, data collection has begun for 1994 diagnoses. Close to 1,000 1994 cases have been abstracted.

Objective 2: Organize the operations and quality control techniques to assure a high. level of data quality.

Progress The Personal Computerized Abstract was designed with a built-in computer report and editing system which is run after each batch of abstracts. Additional integrity reports are run by data processing personnel after each batch of edits to ensure complete and consistent data.

Progress Interfield edits have been installed on PCA. Certain SEER edits which are applicable to SRRHIS have been appended and tested, and are now being used routinely. Related documentation has been sent to MUSC.

Progress Case summaries, as well as the SEER/SRRHIS/STATE Systems Query Search (SOS) are now available on PCA split screen for use in editing.

Progress A set of 20 unedited Georgia abstracts and 20 unedited South Carolina abstracts were exchanged for editing by 
Quality Control staff from both registries. The Georgia Field Staff Supervisor then compared the edits in order to independently assure standardization of editing techniques. Several minor discrepancies were identified and corrected. Dr. Liff reported this data to the Steering Committee.

Progress Case summaries and a Systems Query Search system were made available on PCA split screen for use in SRRHIS editing. All SRRHIS, SEER and Georgia Cancer Registry cases, both reportable and non-reportable, can be called up on SOS, by name, birth date or social security number.

Progress SEER and GCR databases were searched to identify any cases that were eligible for SRRHIS but had not yet been included. As a result, several missed cases were entered into the SRRHIS database.

Objective 3: Implement an-operations protocol compatible with major (SEER, ACoS) surveillance programs.

Progress Using the customized data collection program, Personal Computer Abstract (FCA) the SRRHIS Editor completed the review and verification of cases submitted by the Field Coordinators, hospitals, pathology laboratories and radiation treatment facilities. Computer edit reports and integrity reports were generated.

Progress Preparations were initiated and continued for a death clearance, matching Georgia death tapes for 1991, 1992 and 1993 with the SRRHIS database. An extraction from the 1991-1993 death tapes was done of all persons living in SRRHIS counties and with cancer as a cause of death. This file was matched to the Georgia State database, the SEER database and the SRRHIS database and has generated a "non-match" file. This file will be reviewed by the SRRHIS Editor to identify any cases that may have been missed. The listing of the file has been printed and uploaded to the SRRHIS computer file.

Progress Pathology reports were prepared by coding site, histology 
and physician and entering them into the database. Several mail-merges was completed, in which we generate and send letters to physicians for those cases who were identified through pathology laboratories only and had no demographic information. We sent an abstractor into one urology group office and several other practices where office personnel were reluctant to complete forms. Resistance in a number of offices has been overcome, but a single urology practice is still unwilling to release data. Help in obtaining access has been sought from the local health district.

Objective 5: Establish and maintain a computerized data management system compatible with major surveillance programs.

Progress Work was continued on the enhancement of the data management system to enable us to cross reference and maintain quality control functions.

Progress Abstractors are now using lap top computers for case identification in pathology laboratories and radiation therapy units as well as for abstracting cases on PCA. Mechanisms for channeling and processing these data as . well as SRRHIS cases from all cases received from the Georgia hospital tumor registries are in place and running smoothly. 


\begin{tabular}{|c|c|c|c|c|c|}
\hline \multicolumn{6}{|c|}{$\begin{array}{c}\text { Savannah River Region Health Information System } \\
\text { Cancer Cases by Counties } \\
1991-1994\end{array}$} \\
\hline Counties & 1991 & 1992 & $\underline{1993}$ & 1994 & Total \\
\hline Bryan & 54 & 51 & 40 & 3 & 148 \\
\hline Bulloch & 127 & 87 & 116 & 28 & 358 \\
\hline Burke & 88 & 70 & 55 & 3 & 216 \\
\hline Chatham & 860 & 523 & 416 & 1 & 1800 \\
\hline Columbia & 209 & 244 & 209 & 9 & 671 \\
\hline Effingham & 60 & 48 & 27 & 0 & 135 \\
\hline Evans & 29 & 21 & 19 & 4 & 73 \\
\hline Jefferson & 83 & 91 & 69 & 4 & 247 \\
\hline Jenkins & 36 & 36 & 28 & 1 & 101 \\
\hline McDuffie & 79 & 79 & 81 & 1 & 240 \\
\hline Richmond & 765 & 855 & 702 & 38 & 2360 \\
\hline Screven & $\underline{56}$ & $\underline{53}$ & $\underline{65}$ & $\underline{7}$ & 181 \\
\hline GA. Cases Total & 2446 & 2158 & 1827 & 99 & 6530 \\
\hline South Carolina & $\underline{559}$ & 649 & $\underline{571}$ & 14 & 1793 \\
\hline Total & 3005 & 2807 & 2398 & $1 \overline{13}$ & 8323 \\
\hline
\end{tabular}

Number of Cases as of Mar. 1995 


\begin{tabular}{|c|c|c|c|c|c|}
\hline \multicolumn{6}{|c|}{$\begin{array}{c}\begin{array}{c}\text { Savannah River Region Health Information System } \\
\text { Invasive Georgia Cancer Cases by Site } \\
1991-1994\end{array} \\
\end{array}$} \\
\hline Site & 1991 & 1992 & 1993 & 1924 & Iotal \\
\hline Oral Cavity & 86 & 66 & 52 & 4 & 208 \\
\hline Esophagus & 42 & 28 & 25 & 2 & 97 \\
\hline Stomach & 38 & 40 & 24 & 1 & 103 \\
\hline Colorectal & 268 & 227 & 204 & 11 & 710 \\
\hline Liver & 6 & 10 & 10 & 2 & 28 \\
\hline Pancreas & 56 & 56 & 40 & 1 & 153 \\
\hline Other Digestive & 27 & 29 & 24 & 0 & 80 \\
\hline Lung/Bronchus & 441 & 363 & 263 & 10 & 1077 \\
\hline Other Respiratory/Thoracic & 50 & 45 & 42 & 2 & 139 \\
\hline Melanoma & 49 & 56 & 44 & 5 & 154 \\
\hline Female Breast & 377 & 311 & 281 & 22 & 991 \\
\hline Cervix Uteri & 36 & 43 & 36 & 4 & 119 \\
\hline Corpus ( $\&$ unspec.) Uteri & 44 & 55 & 61 & 5 & 165 \\
\hline Ovary & 44 & 39 & 30 & 3 & 116 \\
\hline Other Female Genital & 6 & 12 & 15 & 1 & 34 \\
\hline Prostate & 261 & 267 & 231 & 5 & 764 \\
\hline Other Male Genital & 10 & 16 & 14 & 0 & 40 \\
\hline Kidney & 55 & 34 & 41 & 0 & 130 \\
\hline Bladder & 61 & 63 & 49 & 4 & 177 \\
\hline Other Urinary Tract & 6 & 7 & 3 & 1 & 17 \\
\hline Thyroid & 22 & 27 & 17 & 0 & 66 \\
\hline Lymphoma & 82 & 70 & 47 & 2 & 201 \\
\hline Leukemia & 40 & 53 & 34 & $\overline{2}$ & 129 \\
\hline Multiple Myeloma & 20 & 14 & 22 & 0 & 56 \\
\hline Unknown & 93 & 78 & .54 & 3 & 228 \\
\hline Other & 94 & 67 & 68 & 3 & 232 \\
\hline Total & $\overline{2314}$ & $\overline{2076}$ & 1731 & 93 & $\overline{6214}$ \\
\hline
\end{tabular}

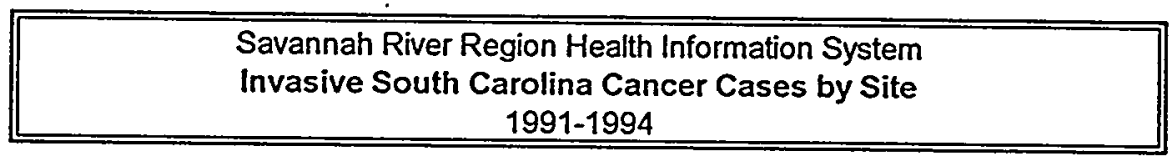

\begin{tabular}{crrrrr}
\hline Site & 1991 & 1992 & 1993 & 1994 & Iotal \\
\hline Oral Cavity & 18 & 17 & 13 & 0 & 48 \\
Esophagus & 8 & 6 & 5 & 0 & 19 \\
Stomach & 6 & 9 & 9 & 1 & 25 \\
Colorectal & 69 & 52 & 47 & 0 & 168 \\
Liver & 4 & 4 & 5 & 0 & 13 \\
Other Digestive & 7 & 6 & 10 & 0 & 23 \\
Pancreas & 7 & 13 & -12 & 0 & 32 \\
Lung/Bronchus & 112 & 98 & 79 & 1 & 290 \\
Other Respiratory/Thoracic & 7 & 25 & 8 & 1 & 41 \\
Melanoma & 15 & 16 & 12 & 1 & 44 \\
Female Breast & 69 & 71 & 95 & 3 & 238 \\
Cervix Uteri & 13 & 11 & 6 & 0 & 30 \\
Corpus (\& unspec.) Uteri & 8 & 13 & 16 & 1 & 38 \\
Ovary & 10 & 11 & 19 & 0 & 40 \\
Other Female Genital & 0 & 4 & 9 & 0 & 13 \\
Prostate & 67 & 85 & 70 & 3 & 225 \\
Other Male Genital & 2 & 5 & 7 & 0 & 14 \\
Kidney & 8 & 20 & 11 & 0 & 39 \\
Bladder & 23 & 21 & 10 & 0 & 54 \\
Other Urinary Tract & 0 & 3 & 1 & 0 & 4 \\
Thyroid & 10 & 8 & 6 & 0 & 24 \\
Lymphoma & 16 & 26 & 18 & 0 & 60 \\
Leukemia & 4 & 11 & 4 & 0 & 19 \\
Multiple Myeloma & 9 & 11 & 6 & 1 & 27 \\
Unknown & 14 & 21 & 1 & 53 \\
Other & 34 & 55 & 25 & 0 & 114 \\
Total & 540 & 618 & 524 & 13 & 1695
\end{tabular}

Note: Includes in situ bladder cancers

Source: Georgia SRRHIS registry, at Georgia Center for Cancer Statistics, Rollins School of Public Health.Emory Univ. March 1995. 


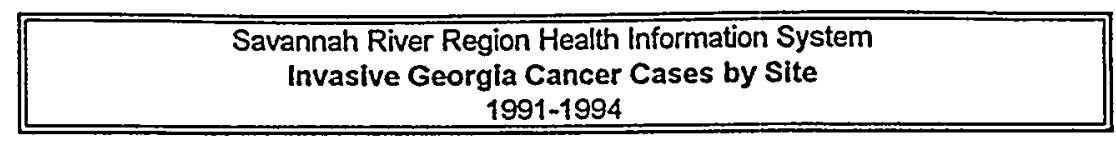

Blacks

\begin{tabular}{crrrrr}
\hline Site & 1991 & 1992 & $19 ! 3$ & 1994 & Iotal \\
\hline Oral Cavity & 32 & 22 & 15 & 2 & 71 \\
Esophagus & 18 & 14 & 10 & 0 & 42 \\
Stomach & 23 & 17 & 12 & 1 & 53 \\
Colorectal & 77 & 57 & 150 & 4 & 198 \\
Liver & 0 & 2 & 3 & 1 & 6 \\
Pancreas & 27 & 20 & 13 & 0 & 60 \\
Other Digestive & 9 & 2 & 6 & 0 & 17 \\
Lung/Bronchus & 105 & 83 & 55 & 4 & 247 \\
Other Respiratory/Thoracic & 14 & 12 & 17 & 0 & 43 \\
Melanoma & 0 & 2 & 3 & 0 & 5 \\
Female Breast & 112 & 90 & 37 & 6 & 295 \\
Cervix Uteri & 17 & 18 & 21 & 1 & 57 \\
Corpus (\& unspec.) Uteri & 15 & 15 & 19 & 1 & 50 \\
Ovary & 16 & 10 & 3 & 0 & 29 \\
Other Female Genital & 2 & 5 & 8 & 0 & 15 \\
Prostate & 89 & 90 & 83 & 2 & 264 \\
Other Male Genital & 1 & 4 & 1 & 0 & 6 \\
Kidney & 12 & 6 & 7 & 0 & 25 \\
Bladder & 10 & 9 & 8 & 2 & 29 \\
Other Urinary Tract & 1 & 0 & 1 & 0 & 2 \\
Thyroid & 7 & 7 & 2 & 0 & 16 \\
Lymphoma & 16 & 11 & 10 & 0 & 37 \\
Leukemia & 16 & 13 & 6 & 0 & 35 \\
Multiple Myeloma & 8 & 3 & 12 & 0 & 23 \\
Unknown & 27 & 23 & 11 & 2 & 63 \\
Other & 29 & 10 & 17 & 0 & 56 \\
Total & 683 & 545 & 490 & 26 & 1744
\end{tabular}

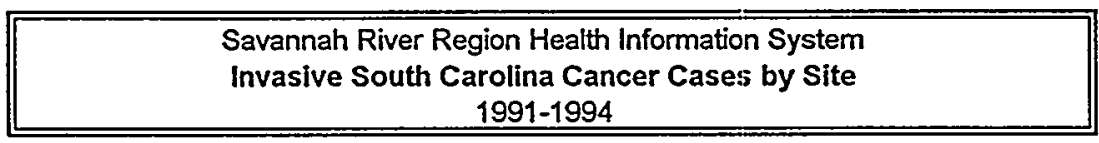

Blacks

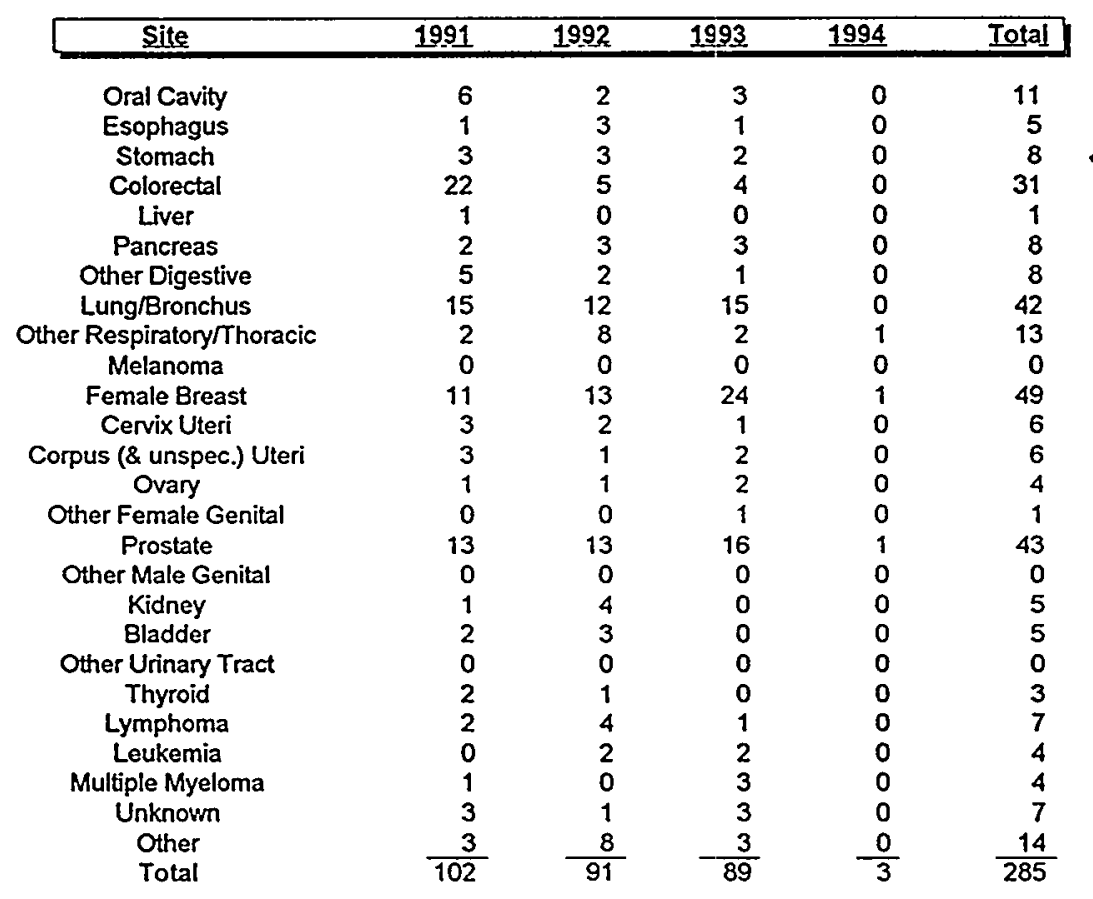

Noxe: Inctudes in shu bladder coses 


\begin{tabular}{|c|c|c|c|c|c|}
\hline \multicolumn{6}{|c|}{$\begin{array}{c}\text { Savannah River Region Health Information System } \\
\text { In Situ Georgia Cancer Cases by Site } \\
1991-1994\end{array}$} \\
\hline Sile & 1991 & 1992 & 1993 & 1094 & Iotal \\
\hline $\begin{array}{c}\text { Oral Cavity } \\
\text { Esophagus } \\
\text { Stomach } \\
\text { Colorectal } \\
\text { Liver } \\
\text { Pancreas } \\
\text { Other Digestive } \\
\text { Lung/Bronchus } \\
\text { Other Respiratory/Thoracic } \\
\text { Melanoma } \\
\text { Female Breast } \\
\text { Cervix Uteri } \\
\text { Corpus (\& unspec.) Uteri } \\
\text { Ovary } \\
\text { Other Female Genital } \\
\text { Prostate } \\
\text { Other Male Genital } \\
\text { Kidney } \\
\text { Bladder } \\
\text { Other Urinary Tract } \\
\text { Thyroid } \\
\text { Lymphoma } \\
\text { Multiple Myeloma } \\
\text { Loukemia } \\
\text { Unknown } \\
\text { Other } \\
\text { Total }\end{array}$ & $\begin{array}{r}2 \\
0 \\
1 \\
18 \\
0 \\
0 \\
0 \\
0 \\
3 \\
4 \\
41 \\
25 \\
1 \\
0 \\
10 \\
1 \\
0 \\
0 \\
24 \\
1 \\
0 \\
0 \\
0 \\
0 \\
0 \\
1 \\
132\end{array}$ & $\begin{array}{r}1 \\
0 \\
0 \\
11 \\
0 \\
0 \\
0 \\
3 \\
3 \\
9 \\
31 \\
1 \\
2 \\
0 \\
9 \\
0 \\
0 \\
0 \\
11 \\
0 \\
0 \\
0 \\
0 \\
0 \\
0 \\
1 \\
82\end{array}$ & $\begin{array}{r}1 \\
1 \\
0 \\
21 \\
0 \\
0 \\
1 \\
1 \\
4 \\
8 \\
38 \\
0 \\
2 \\
0 \\
13 \\
1 \\
0 \\
0 \\
4 \\
1 \\
0 \\
0 \\
0 \\
0 \\
0 \\
1 \\
97\end{array}$ & $\begin{array}{l}0 \\
0 \\
0 \\
1 \\
0 \\
0 \\
0 \\
0 \\
0 \\
0 \\
2 \\
2 \\
0 \\
0 \\
0 \\
1 \\
0 \\
0 \\
0 \\
0 \\
0 \\
0 \\
0 \\
0 \\
0 \\
0 \\
0 \\
6\end{array}$ & $\begin{array}{r}4 \\
1 \\
1 \\
51 \\
0 \\
0 \\
1 \\
4 \\
10 \\
23 \\
112 \\
26 \\
5 \\
0 \\
33 \\
2 \\
0 \\
0 \\
39 \\
2 \\
0 \\
0 \\
0 \\
0 \\
0 \\
3 \\
317\end{array}$ \\
\hline
\end{tabular}

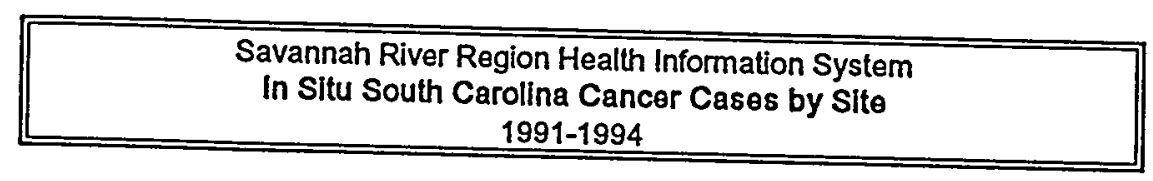

\begin{tabular}{|ccccc}
\hline Sito & 1991 & 1992 & 1993 & 1994 \\
\hline Oral Cavity & 0 & 0 &
\end{tabular}

\begin{tabular}{|c|c|c|c|c|c|}
\hline Oral Cavity & 0 & 0 & & & \\
\hline Esophagus & 0 & 0 & $\begin{array}{l}1 \\
0\end{array}$ & 0 & 1 \\
\hline Stomach & 0 & 0 & 0 & 0 & 0 \\
\hline Colorectal & 2 & 3 & 2 & 0 & 0 \\
\hline Liver & 0 & 0 & $\begin{array}{l}2 \\
0\end{array}$ & 0 & 7 \\
\hline Pancreas & 0 & 0 & $\begin{array}{l}0 \\
0\end{array}$ & 0 & 0 \\
\hline Other Digestive & 0 & 0 & 0 & 0 & 0 \\
\hline Lung/Bronchus & $\mathbf{0}$ & 0 & 2 & 0 & 2 \\
\hline Other Respiratory/Thoracic & 0 & & 0 & 0 & 0 \\
\hline Melanoma & 1 & 1 & 0 & $\mathbf{0}$ & 1 \\
\hline Female Breast & 11 & 1 & 2 & $\mathbf{0}$ & 4 \\
\hline Corvix Uteri & 1 & 9 & 16 & 1 & 37 \\
\hline Corpus ( \& unspec.) Uteri & 0 & 5 & 15 & 0 & 21 \\
\hline Ovary & 0 & 2 & 0 & 0 & 2 \\
\hline Other Female Genital & 0 & 0 & 0 & 0 & 0 \\
\hline Prostate & 1 & 4 & 6 & 0 & 11 \\
\hline Other Male Genital & 0 & 0 & $\mathbf{0}$ & 0 & 0 \\
\hline Kidney & $\mathbf{0}$ & 0 & $\mathbf{0}$ & 0 & $\mathbf{0}$ \\
\hline Bladder & $\mathbf{0}$ & 0 & 0 & 0 & 0 \\
\hline $\begin{array}{l}\text { Bladder } \\
\text { Other Urinary Tract }\end{array}$ & 2 & 3 & 1 & $\mathbf{0}$ & 6 \\
\hline & 0 & 0 & 0 & 0 & 0 \\
\hline Thyroid & 0 & $\mathbf{0}$ & 0 & $\mathbf{0}$ & $\mathbf{0}$ \\
\hline Lymphoma & 0 & $\mathbf{0}$ & 0 & $\mathbf{0}$ & 0 \\
\hline Multiple Myeloma & 0 & $\mathbf{0}$ & 0 & $\mathbf{0}$ & 0 \\
\hline Loukemia & 0 & 0 & 0 & 0 & 0 \\
\hline Unknown & 0 & 0 & 0 & 0 & 0 \\
\hline Other & $\frac{1}{10}$ & 3 & 2 & $\underline{0}$ & 6 \\
\hline Total & & 31 & 47 & 1 & 98 \\
\hline
\end{tabular}

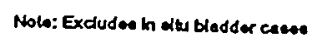


DE-FG09-91SR18217-4

\section{APPENDIX K}

Steering Committee Agendas 


\section{TENTATIVE AGENDA \\ SAVANNAH RIVER REGION HEALTH INFORMATION SYSTEM \\ SteEring CommitteE \\ ThURSDAY, JULY 14, 1994 \\ EHRHARDT HALL \\ EHRHARDT, SC}

\section{SCHEDULE}

7:00 p.m. Introductory Remarks and Minutes

7:10 p.m. Progress and Subcommittee

$$
\begin{gathered}
\text { Reports- GA Progress Report } \\
\text { - SC Progress Report } \\
\text { - Legislative Issues } \\
\text { - SC State Cancer Registry } \\
\text { - Membership }
\end{gathered}
$$

7:30 p.m.

$\begin{array}{ll}\text { 8:00 p.m. } & \begin{array}{l}\text { Discussion: "Draft Report of } \\ \text { 1991 SRRHIS Cancer Cases" }\end{array} \\ \text { 8:30 p.m. } & \begin{array}{l}\text { Discussion: "Alternative } \\ \text { Funding for the SRRHIS } \\ \text { Registry" }\end{array} \\ \text { 9:00 p.m. } & \text { Next Meeting Site } \\ \text { 9:10 p.m. } & \text { Adjourn }\end{array}$

"Redefining Boundaries of a Geographic Cancer Registry Through Cooperation and Collaboration: SRRHIS"

Mr. Andrew Rea Chairman

Dr. Jonathan Liff Dr. John Dunbar Mr. Tom Hendrix Ms. Brenda Nickerson Ms. Susan Bolick Dr. Bill Irby

.Dr. Daniel Lackland Medical University of South Carolina

Dr. Jonathan Liff Emory University

Mr. Andrew Rea Chairman, SRRHIS Steering Comittee Committee 
TENTATIVE AGENDA

SAVANNAH RIVER REGION HEALTh INFORMATION SySTEM

STEERING COMMITTEE

WEDNESDAY, NOVEMHER 9, 1994

HOLIDAY INN - WEST

1075 STEVENS CREEK ROAD

SCHEDULE

Augusta, GA

5:30 p.m. Dinner

7:00 p.m. Introductory Remarks, Minutes Replacement: Steering Committee Vice President

7:15 p.m. Progress and Subcommittee Reports Reports- GA Progress Report - SC Progress Report - Legislative Issues

- Membership

7:30 p.m. "National Program for Cancer Registries" CDC Grant

8:00 p.m. Discussion: Alternative Funding for the SRRHIS Registry
a. State Registry - CDC
b. Other
$8: 45$
Next Meeting Site
9:00 p.m.
Adjourn

Steering Committee Members

SRRHIS Staff

Mr. Andrew Rea

Chairman

Dr. Jonathan Liff

Dr. John Dunbar

Mr. Tom Hendrix

Ms. Brenda Nickerson

Dr. Bill Irby

Ms. Brenda Nickerson

Ms. Susan Bolick

Mr. Andrew Rea

Chairman 